\title{
Sulfur K-Edge X-ray Absorption Spectroscopy and Density Functional Theory Calculations on Monooxo MolV and Bisoxo MoVI Bis-dithiolenes: Insights into the Mechanism of Oxo Transfer in Sulfite Oxidase and Its Relation to the Mechanism of DMSO Reductase
}

\section{Citation}

Ha, Yang, Adam L. Tenderholt, Richard H. Holm, Britt Hedman, Keith O. Hodgson, and Edward I. Solomon. 2014. "Sulfur K-Edge X-ray Absorption Spectroscopy and Density Functional Theory Calculations on Monooxo MolV and Bisoxo MoVI Bis-dithiolenes: Insights into the Mechanism of Oxo Transfer in Sulfite Oxidase and Its Relation to the Mechanism of DMSO Reductase." Journal of the American Chemical Society 136 (25): 9094-9105. doi:10.1021/ja503316p. http:// dx.doi.org/10.1021/ja503316p.

\section{Published Version}

doi:10.1021/ja503316p

\section{Permanent link}

http://nrs.harvard.edu/urn-3:HUL.InstRepos:17295597

\section{Terms of Use}

This article was downloaded from Harvard University's DASH repository, and is made available under the terms and conditions applicable to Other Posted Material, as set forth at http:// nrs.harvard.edu/urn-3:HUL.InstRepos:dash.current.terms-of-use\#LAA

\section{Share Your Story}

The Harvard community has made this article openly available.

Please share how this access benefits you. Submit a story. 


\title{
Sulfur K-Edge X-ray Absorption Spectroscopy and Density Functional Theory Calculations on Monooxo $\mathrm{Mo}^{\mathrm{IV}}$ and Bisoxo Mo ${ }^{\mathrm{Vl}} \mathrm{Bis}-$ dithiolenes: Insights into the Mechanism of Oxo Transfer in Sulfite Oxidase and Its Relation to the Mechanism of DMSO Reductase
}

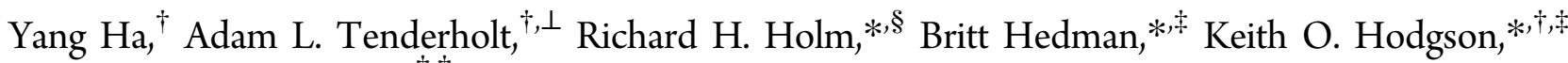 \\ and Edward I. Solomon $*, \dagger, \ddagger$ \\ ${ }^{\dagger}$ Department of Chemistry, Stanford University, Stanford, California 94305, United States \\ ${ }^{\ddagger}$ Stanford Synchrotron Radiation Lightsource, SLAC, Stanford University, Menlo Park, California 94025, United States \\ ${ }^{\S}$ Department of Chemistry and Chemical Biology, Harvard University, Cambridge, Massachusetts 02138, United States
}

\section{Supporting Information}

ABSTRACT: Sulfur K-edge X-ray absorption spectroscopy (XAS) and density functional theory (DFT) calculations have been used to determine the electronic structures of two complexes $\left[\mathrm{Mo}^{\mathrm{IV}} \mathrm{O}(\mathrm{bdt})_{2}\right]^{2-}$ and $\left[\mathrm{Mo}^{\mathrm{VI}} \mathrm{O}_{2}(\mathrm{bdt})_{2}\right]^{2-}(\mathrm{bdt}=$ benzene-1,2-dithiolate $(2-)$ ) that relate to the reduced and oxidized forms of sulfite oxidase (SO). These are compared with those of previously studied dimethyl sulfoxide reductase (DMSOr) models. DFT calculations supported by the data are extended to evaluate the reaction coordinate for oxo transfer to a phosphite ester substrate. Three possible transition states are found with the one at lowest energy, stabilized by a $\mathrm{P}-\mathrm{S}$ interaction, in good agreement with experimental kinetics data. Comparison of both oxo transfer reactions shows that in DMSOr, where the oxo is transferred from the substrate to the metal ion, the oxo transfer induces electron transfer, while in SO, where the oxo transfer is from the metal site to the substrate, the electron transfer initiates oxo transfer. This difference in reactivity is related to the difference in frontier molecular orbitals (FMO) of the metal-oxo and substrate-oxo bonds. Finally, these experimentally related calculations are extended to oxo transfer by sulfite oxidase. The presence of only one dithiolene at the enzyme active site selectively activates the equatorial oxo for transfer, and allows facile structural reorganization during turnover.

\section{INTRODUCTION}

Molybdenum is the one second row transition metal that has been found in almost all forms of life, including microorganisms, plants and animals. ${ }^{1}$ It is part of a multinuclear active site in the FeMoco cofactor in nitrogenase, ${ }^{2,3}$ while most other enzymes have a mononuclear center, which is redoxactive between the $\mathrm{Mo}^{\mathrm{IV}}$ and $\mathrm{Mo}^{\mathrm{VI}}$ oxidation states and has pyranopterin-dithiolene ligands. ${ }^{4-7}$ The $\mathrm{Mo}^{\mathrm{V}}$ oxidation state is not directly involved in the oxo transfer reaction, but is involved as enzymes and models cycle between $\mathrm{Mo}^{\mathrm{IV}}\left(\mathrm{d}^{2}\right)$ and $\mathrm{Mo}^{\mathrm{VI}}\left(\mathrm{d}^{0}\right)$ oxidation states. ${ }^{8}$ These mononuclear molybdenum enzymes have been divided into three families: dimethyl sulfoxide (DMSO) reductases, sulfite oxidases, and xanthine oxidases. ${ }^{6}$ DMSO reductase and sulfite oxidase catalyze oxotransfer reactions. DMSO reductase reduces DMSO to DMS (dimethyl sulfide), with oxo transfer to the Mo center, which converts from a $\mathrm{Mo}^{\mathrm{IV}}$ desoxo (i.e., no oxo ligand, but a with an alkoxide-Mo bond) to a $\mathrm{Mo}^{\mathrm{VI}}$ monooxo species. Sulfite oxidase (SO) transfers an oxo ligand to substrates, converting the Mo center from a $\mathrm{Mo}^{\mathrm{VI}}$ bisoxo to a $\mathrm{Mo}^{\mathrm{IV}}$ monooxo species. ${ }^{5}$
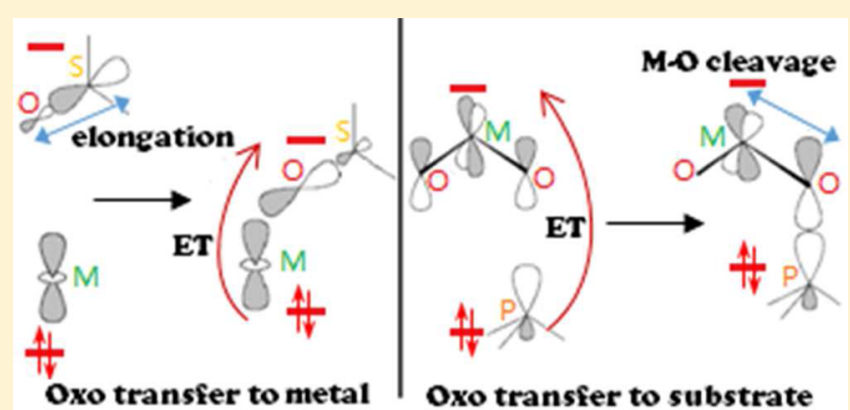

Model complexes have been synthesized and characterized that mimic either the structure and/or activity for these enzyme active sites. These have greatly assisted in developing an understanding of the mechanisms of oxo transfer to $\mathrm{Mo}^{\mathrm{IV}}$ and oxo transfer from $\mathrm{Mo}^{\mathrm{VI}} \mathrm{O}_{2} \cdot{ }^{9}$ A number of experimental and theoretical studies have focused on DMSO reductase reactions to understand the geometric and electronic structural contributions to function. ${ }^{10-15}$ Our previous study of $\left[\mathrm{Mo}^{\mathrm{IV}}(\mathrm{OSi})(\mathrm{bdt})_{2}\right]^{-}$and $\left[\mathrm{Mo}{ }^{\mathrm{VI}} \mathrm{O}(\mathrm{OSi})(\mathrm{bdt})_{2}\right]^{-}$complexes $\left(\mathrm{OSi}=\left[\mathrm{OSiPh}_{2}{ }^{t} \mathrm{Bu}\right]^{-}, \mathrm{bdt}=\right.$ benzene-1,2-dithiolate $(2-)$, Figure $1 \mathrm{~B}, \mathrm{D})$, provided the following insight into the nature of the DMSO oxo transfer reaction: ${ }^{10}(1)$ the dithiolene ligands are innocent (i.e., not redox-active), but are strong $\pi$-donors that stabilize the singlet ground state of the $\mathrm{Mo}^{\mathrm{IV}}$ in the absence of a strong oxo ligand; and (2) in the oxo transfer from the DMSO to the $\mathrm{Mo}^{\mathrm{IV}}$ center, the $\mathrm{S}-\mathrm{O}$ bond elongation polarizes the bond, and decreases the energy gap between frontier molecular

Received: April 10, 2014

Published: June 2, 2014 


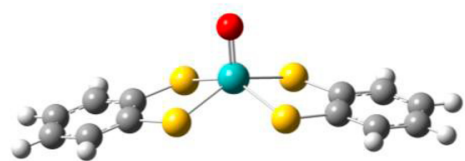

A) $\left[\mathrm{Mo}^{\mathrm{IV} O}(\mathrm{bdt})_{2}\right]^{2-}$

Exp: Mo=O 1.70 Mo-S 2.40

Cal: Mo=0 1.69 Mo-S 2.43

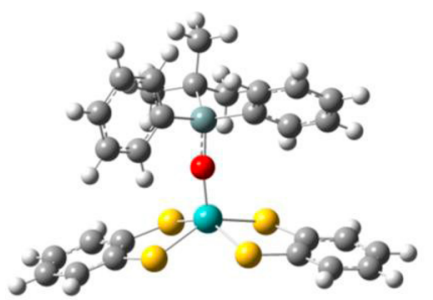

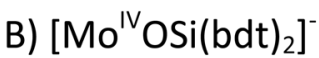

Exp: Mo-O 1.84 Mo-S 2.35

Cal: Mo-O 1.86 Mo-S 2.37

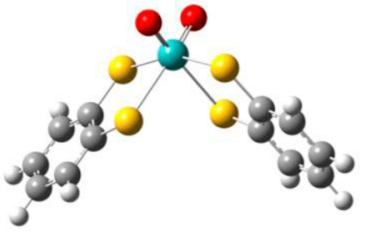

C) $\left[\mathrm{Mo}^{\mathrm{VI}} \mathrm{O}_{2}(\mathrm{bdt})_{2}\right]^{2-}$

Exp: Mo=0 1.74 Mo-S* 2.62 Mo-S 2.46

Cal: Mo=O 1.73 Mo-S* 2.66 Mo-S 2.47

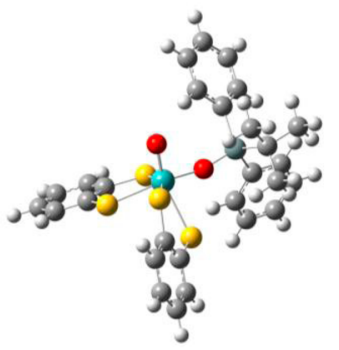

D) $\left[\mathrm{Mo}{ }^{\mathrm{VI}} \mathrm{O}(\mathrm{OSi})(\mathrm{bdt})_{2}\right]^{-}$

$\begin{array}{lllll}\text { Exp: } & \text { Mo=O } & 1.72 & \text { Mo-S* } & 2.49 \\ & \text { Mo-O } & 1.93 & \text { Mo-S } & 2.43 \\ \text { Cal: } & \text { Mo=O } & 1.70 & \text { Mo-S* } & 2.52 \\ & \text { Mo-O } & 1.94 & \text { Mo-S } & 2.46\end{array}$

Figure 1. Crystal and geometry optimized structures of the complexes in this study. Bond distances in angstroms ( $\AA$ ) are listed below the structure. Mo-S* indicates the sulfur atom that is trans-axial to the oxo ligand. In panel $\mathrm{D}$, similar Mo-S bond distances were averaged.

orbitals (FMOs, the LUMO on the substrate and the HOMO occupied d-orbital on the $\mathrm{Mo}^{\mathrm{IV}}$ ), allowing the transfer of the electron pair from Mo to the substrate to complete the oxo transfer.

There have also been a number of sulfite oxidase model studies. Holm and co-workers have synthesized a model that matched the native enzyme structure well, but there was no reported reactivity. ${ }^{16}$ The Sarkar group measured the kinetics of oxo transfer from $\left[\mathrm{Mo}^{\mathrm{VI}} \mathrm{O}_{2}(\mathrm{mnt})_{2}\right]^{2-}(\mathrm{mnt}=$ maleonitriledithiolate(2-)) to $\mathrm{HSO}_{3}{ }^{-}$and found Michaelis-Menten kinetics. ${ }^{17}$ Other model studies focused on the transfer of an oxo group from a $\mathrm{Mo}^{\mathrm{VI}} \mathrm{O}_{2}$ species to phosphine substrates. Hall and co-workers studied the reaction: $\left[\mathrm{Mo}^{\mathrm{VI}} \mathrm{O}_{2}(t \mathrm{BuL}-\mathrm{NS})_{2}\right]+$ $\mathrm{PMe}_{3} \rightarrow\left[\mathrm{Mo}^{\mathrm{IV}} \mathrm{O}(t \mathrm{BuL}-\mathrm{NS})_{2}\right]+\mathrm{OPMe}_{3}$ computationally ${ }^{18}$ based on the experimental data of Holm an co-workers on this reaction. ${ }^{19}$ The $t \mathrm{BuL}-\mathrm{NS}$ ligand had nonconjugated nitrogen and sulfur groups bound to the Mo. Basu and co-workers ${ }^{20}$ studied the reaction: $\left[\mathrm{L}^{\mathrm{iPr}} \mathrm{MoO}_{2}(\mathrm{OPh})\right]+\mathrm{PMe}_{3} \rightarrow\left[\mathrm{L}^{\mathrm{iPr}} \mathrm{MoO}-\right.$ (OPh)-Solvent $]+\mathrm{O}=\mathrm{PMe}_{3}$ both experimentally and computationally, where $\mathrm{L}^{\mathrm{iPr}}$ is a tridentate ligand with nitrogens bound to $\mathrm{Mo}^{20}$ Neither study utilized the dithiolene ligation present in the enzymes. There are also studies to evaluate electronic structures of model complexes that do not have oxo transfer reactivity, but contain dithiolene ligation. ${ }^{21,22}$ The Holm group has synthesized a series of $\mathrm{Mo}^{\mathrm{IV}} \mathrm{O}$ and $\mathrm{Mo}^{\mathrm{VI}} \mathrm{O}_{2}$ bisdithiolene complexes, characterized their geometric structures and showed that they undergo oxo transfer to phosphite esters with well determined kinetics parameters for the reaction ${ }^{23}$

$$
\begin{aligned}
& {\left[\mathrm{Mo}^{\mathrm{VI}} \mathrm{O}_{2}(\mathrm{mnt})_{2}\right]^{2-}+\mathrm{P}(\mathrm{OMe})_{3}} \\
& \quad \rightarrow\left[\mathrm{Mo}^{\mathrm{IV}} \mathrm{O}(\mathrm{mnt})_{2}\right]^{2-}+\mathrm{O}=\mathrm{P}(\mathrm{OMe})_{3}
\end{aligned}
$$

The focus of the current study is to use spectroscopic and computational methods to determine the electronic structure of these Mo dithiolene complexes, and use experimentally calibrated calculations to evaluate this oxo transfer reaction. The goal is to understand this and the other oxo transfers to substrate on a molecular level and to compare these to the reaction coordinate obtained for DMSO reductase, which involves oxo transfer from substrate to $\mathrm{Mo}^{\mathrm{IV}}$.

In our previous study of the DMSO reductase reaction, S Kedge X-ray absorption spectroscopy (XAS) was used to experimentally determine the electronic structures of the dithiolene coordinated Mo centers. ${ }^{10}$ The transition of a $S$ 1s electron into the low-lying unoccupied valence orbitals, which have some $S 3 p$ character mixed into predominantly metal dorbitals, leads to pre-edge features in XAS. The energies of the pre-edge transitions reflect the energies of these unoccupied Mo d-orbitals, which depend on the effective nuclear charge $\left(Z_{\text {eff }}\right)$ of the metal and the ligand field strength. ${ }^{24}$ Thus, changing from $\mathrm{Mo}^{\mathrm{IV}}$ to $\mathrm{Mo}^{\mathrm{VI}}$ will shift the pre-edge to lower energy, while binding a strong (i.e., oxo) ligand will shift the $\mathrm{d} \sigma$ and $\mathrm{d} \pi$ orbitals to higher energy. Of particular utility is that the intensity of a pre-edge transition is proportional to the amount of $S 3 p$ character mixed into the unoccupied metal $d$ orbitals due to covalent bonding. Thus, the metal-sulfur bond covalencies can be measured experimentally.

The intensity of a pre-edge peak $D_{0}$ is given by

$$
D_{0}=\sum c \alpha^{2}\left|\left\langle S_{1 s}|r| S_{3 p}\right\rangle\right|^{2}=\frac{\alpha^{2} h}{3 N} I_{s}
$$

where $\alpha^{2}$ is the bond covalency (i.e., sulfur $\mathrm{p}$ character mixed into a metal $\mathrm{d}$ orbital), $\mathrm{N}$ is the total number of sulfurs bound to the metal, $h$ is the total number of d electron holes, and $I_{\mathrm{s}}$ is 
the electric dipole integral, which is dependent on the $Z_{\text {eff }}$ of the $S$ ligand and has been experimentally determined in reference. ${ }^{25}$ Density functional theory (DFT) calculations supported by the $S$ K-edge XAS data can then provide further insight into the bonding and be used to explore the reactivity. ${ }^{26}$

In this study, $S$ K-edge XAS is used to experimentally determine the electronic structures of the dithiolene complexes $\left[\mathrm{Mo}^{\mathrm{IV}} \mathrm{O}(\mathrm{bdt})_{2}\right]^{2-}$ and $\left[\mathrm{Mo}^{\mathrm{VI}} \mathrm{O}_{2}(\mathrm{bdt})_{2}\right]^{2-}$ (Figure 1A,C, bdt $=$ benzene-1,2-dithiolate $(2-))$ that model the oxo atom transfer reaction of SO. These data are correlated to DFT calculations, and the calculations are used to evaluate oxo transfer from $\mathrm{Mo}^{\mathrm{VI}} \mathrm{O}_{2}{ }^{2-}$ to trimethylphosphite substrate. The nature of this reaction is then compared to our previous results ${ }^{10}$ on oxo transfer from DMSO to a $\mathrm{Mo}^{\mathrm{IV}}$ dithiolene complex. This study provides new insight into these oxo transfer reactions, which are found to be fundamentally different. The DMSO reductase reaction involves a late transition state where oxo transfer leads to electron transfer, while the sulfite oxidase reaction has an early transition state with electron transfer inducing the oxo transfer. This study further considers the intrinsic barriers of both sets of structures for both reactions and is extended to consider the active site reactivity of SO.

\section{EXPERIMENTAL SECTION}

2.1. Sample Preparation. The $\left[\mathrm{Mo}^{\mathrm{IV}} \mathrm{O}(\mathrm{bdt})_{2}\right]^{2-}$ and $\left[\mathrm{Mo}^{\mathrm{VI}} \mathrm{O}_{2}(\mathrm{bdt})_{2}\right]^{2-}$ complexes were prepared as in the literature. ${ }^{27}$

2.2. S K-Edge XAS Data Collection and Analysis. All sulfur Kedge XAS data were measured at the Stanford Synchrotron Radiation Lightsource (SSRL) using the 54-pole wiggler beamline 6-2 operating in high field mode of $10 \mathrm{kG}$ with a Ni-coated harmonic rejection mirror and a fully tuned $\mathrm{Si}(111)$ crystal monochromator. Details of the beamline configuration are given in ref 25 . The solid samples were ground into fine powders in an inert atmosphere $\left(\mathrm{N}_{2}\right)$ dry glovebox where the $\mathrm{O}_{2}$ level was less than $1 \mathrm{ppm}$ and dispersed as thinly as possible on Mylar tape to minimize potential self-absorption. A $6 \mu \mathrm{m}$ thick, sulfur-free polypropylene front window was used to prevent sample exposure to air upon mounting in the sample box. The photon energy was calibrated to the maximum of the first pre-edge feature of $\mathrm{Na}_{2} \mathrm{~S}_{2} \mathrm{O}_{3} \cdot 5 \mathrm{H}_{2} \mathrm{O}$ at $2472.02 \mathrm{eV}$. A total of 3-5 scans were measured for each sample to ensure reproducibility. Raw data were calibrated and averaged using MAVE in the EXAFSPAK software package. ${ }^{28}$ With the use of the PySpline program, ${ }^{29}$ the background was removed from all spectra by fitting a second-order polynomial to the pre-edge region and subtracting it from the entire spectrum. Normalization of the data was accomplished by fitting a flat second-order polynomial or straight line to the post-edge region and normalizing the edge jump to 1.0 at $2490.0 \mathrm{eV}^{24}$ Since the post-edge region also contains intensity from the $\mathrm{Mo}_{2}$-edge, the data were further scaled such that the region between the $\mathrm{S} \mathrm{K}$-edge and $\mathrm{Mo} \mathrm{L}_{3}$-edge had the same intensity as the corresponding region of a tungsten dithiolene complex. ${ }^{10}$ The error from background subtraction and normalization is less than $1 \%$. Intensities of the pre-edge features were obtained by fitting the spectra with peaks having pseudo-Voigt line shape peaks with 1:1 Lorentzian to Gaussian contributions, using the EDG_FIT program. ${ }^{28}$ The reported intensity values were based on the average of 10-12 good fits. The intensities of the S $1 \mathrm{~s} \rightarrow \mathrm{C}-\mathrm{S} \pi^{*} / \sigma^{*}$ transitions at $\sim 2473.8$ $\mathrm{eV}$ were based on previously published values for similar complexes, ${ }^{10}$ where these edge features were better resolved, allowing for $\pm 10 \%$ variation of the intensities and peak widths. The error from the fitting procedure was less than $10 \%$. The fitted intensities were converted to $\% \mathrm{~S} 3 \mathrm{p}$ character using eq 1 , where $D_{0}$ is the peak area and the value of $I_{s}$ was set at $14.1{ }^{10}$ the same as previously published results for similar complexes.

2.3. DFT Calculations. DFT calculations were performed using the Gaussian 09 package ${ }^{30}$ with both the pure functional BP86 (Becke GGA exchange with Perdew 1986 nonlocal correlation ${ }^{31,32}$ ) and the hybrid functional B3LYP (Becke GGA exchange including 20\%
Hartree-Fock mixing and Lee, Yang, and Parr correlation effects ${ }^{33}$ ), using the SDD basis set (triple- $\zeta$ quality with effective core potential) on the Mo atom, ${ }^{34} 6-311 \mathrm{G}(\mathrm{d})$ basis set on the $\mathrm{S}, \mathrm{O}, \mathrm{N}$ and $\mathrm{P}$ atoms and 6-31G(d) on $\mathrm{C}$ and $\mathrm{H}$ atoms. Both functionals gave similar results, and only the B3LYP results are reported here (BP86 results given in Table S1). The geometry optimizations ${ }^{35}$ were performed starting with the published crystal structures. Frequency calculations showed no imaginary frequencies for both reactants and products. All calculations used the polarized continuum model $(\mathrm{PCM})^{36}$ in acetonitrile. Mulliken populations and Mayer bond orders were obtained using the QMForge program, which makes extensive use of the cclib library. ${ }^{37,38}$ For reaction coordinate studies, intrinsic reaction coordinate (IRC) calculations were run after the frequency calculation at the transition state (only 1 imaginary frequency) to ensure that the pathway connects the transition state to both the reactant and product.

\section{RESULTS AND ANALYSIS}

3.1. Electronic Structures. 3.1.1. S K-Edge XAS Data. The sulfur K-edge XAS spectra for the monooxo $\mathrm{Mo}^{\mathrm{IV}}$ and bisoxo $\mathrm{Mo}^{\mathrm{VI}}$ bis-dithiolene complexes are shown in Figure 2. The spectra of the $\left[\mathrm{Mo}^{\mathrm{IV}}(\mathrm{OSi})(\mathrm{bdt})_{2}\right]^{-}$and $\left[\mathrm{Mo}^{\mathrm{VI}} \mathrm{O}(\mathrm{OSi})(\mathrm{bdt})_{2}\right]^{-}$ complexes are also included for reference. The $\left[\mathrm{Mo}^{\mathrm{IV}} \mathrm{O}\right.$ $\left.(\mathrm{bdt})_{2}\right]^{2-}$ complex (Figure 2A) has a dominant feature at

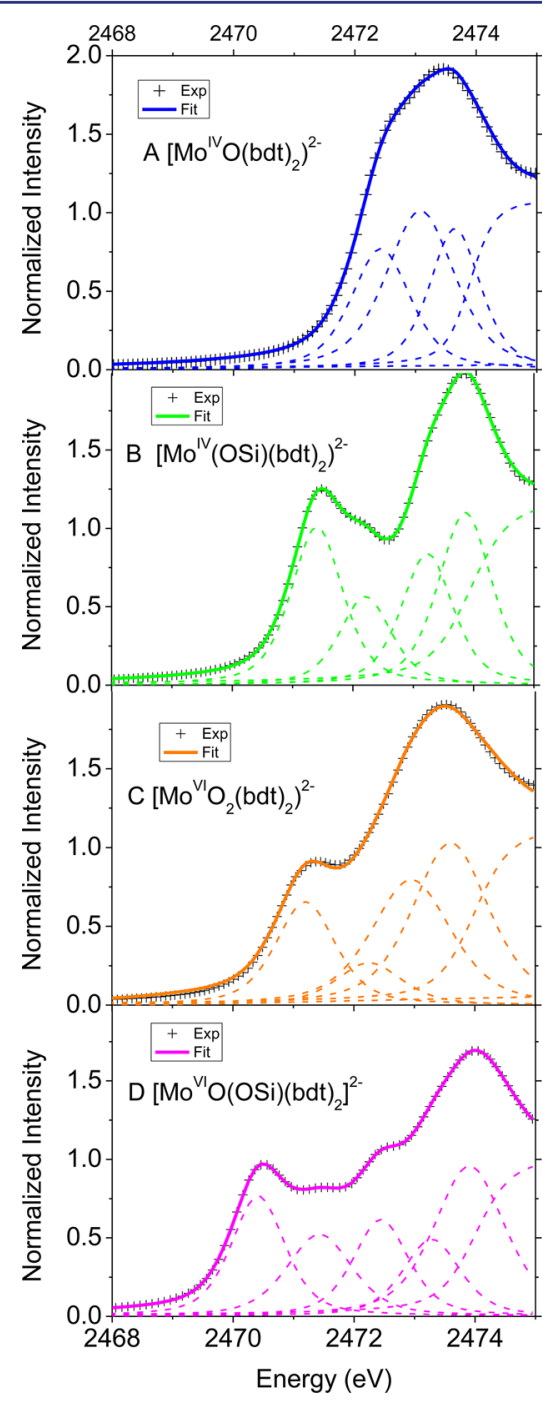

Figure 2. $\mathrm{S}$ K-edge XAS spectra of (A) $\left[\mathrm{Mo}^{\mathrm{IV}} \mathrm{O}(\mathrm{bdt})_{2}\right]^{2-}$, (B) $\left[\mathrm{Mo}^{\mathrm{IV}}(\mathrm{OSi})(\mathrm{bdt})_{2}\right]^{-},(\mathrm{C})\left[\mathrm{Mo}^{\mathrm{VI}} \mathrm{O}_{2}(\mathrm{bdt})_{2}\right]^{2-}$, and (D) $\left[\mathrm{Mo}^{\mathrm{VI}} \mathrm{O}(\mathrm{OSi})-\right.$ (bdt) $\left.{ }_{2}\right]^{-}$. 
Table 1. Experimental and Theoretical S Covalency in Mo Bis-dithiolene Complexes

\begin{tabular}{|c|c|c|c|c|c|c|c|c|}
\hline \multirow[b]{2}{*}{ complex } & \multirow[b]{2}{*}{ orbital } & \multicolumn{5}{|c|}{ S K-edge XAS } & \multicolumn{2}{|c|}{ DFT } \\
\hline & & $E(\mathrm{eV})$ & $D_{\mathrm{o}}$ & $h$ & S p (\%) & $\mathrm{RE}(\mathrm{eV})^{a}$ & $\mathrm{~S} p(\%)$ & $\mathrm{RE}(\mathrm{eV})$ \\
\hline \multirow[t]{2}{*}[\mathrm{Mo}^{\mathrm{IV}}\mathrm{O}(\mathrm{bdt})_{2}]{$^{2-}$} & $\mathrm{d}_{x z} / \mathrm{d}_{y z}$ & 2472.4 & 1.12 & 4 & 38 & 0 & 31 & 0 \\
\hline & $\mathrm{d}_{x y} / \mathrm{d}_{z}^{2}$ & 2473.1 & 1.36 & 4 & 59 & 0.7 & 59 & 0.7 \\
\hline \multirow[t]{4}{*}[\mathrm{Mo}^{\mathrm{IV}}\mathrm{O}_{2}(\mathrm{bdt})_{2}]{$^{2-}$} & $\mathrm{d}_{y z} / \mathrm{d}_{y}^{2}(\mathrm{O}$ out of plane $\pi+/ \pi-)$ & 2471.2 & 0.79 & 4 & 33 & -1.3 & 31 & -1.2 \\
\hline & $\mathrm{d}_{x-z}^{2}{ }^{2}(\mathrm{O}$ in plane $\pi+)$ & 2472.2 & 0.67 & 2 & 15 & -0.3 & 10 & -0.3 \\
\hline & $\mathrm{d}_{x-y}^{2}{ }^{2}(\mathrm{O}$ in plane $\sigma+)$ & 2473.0 & 1.02 & 2 & 53 & 0.6 & 38 & 0.6 \\
\hline & $\mathrm{d}_{x z}(\mathrm{O}$ in plane $\sigma-)$ & Not shown & NA & 2 & NA & NA & 23 & 2.5 \\
\hline
\end{tabular}

${ }^{a} \mathrm{RE}$ stands for Relative Energy. We use the lowest pre-edge energy in $\left[\mathrm{Mo}^{\mathrm{IV}} \mathrm{O}(\mathrm{bdt})_{2}\right]^{2-}$ as a reference.
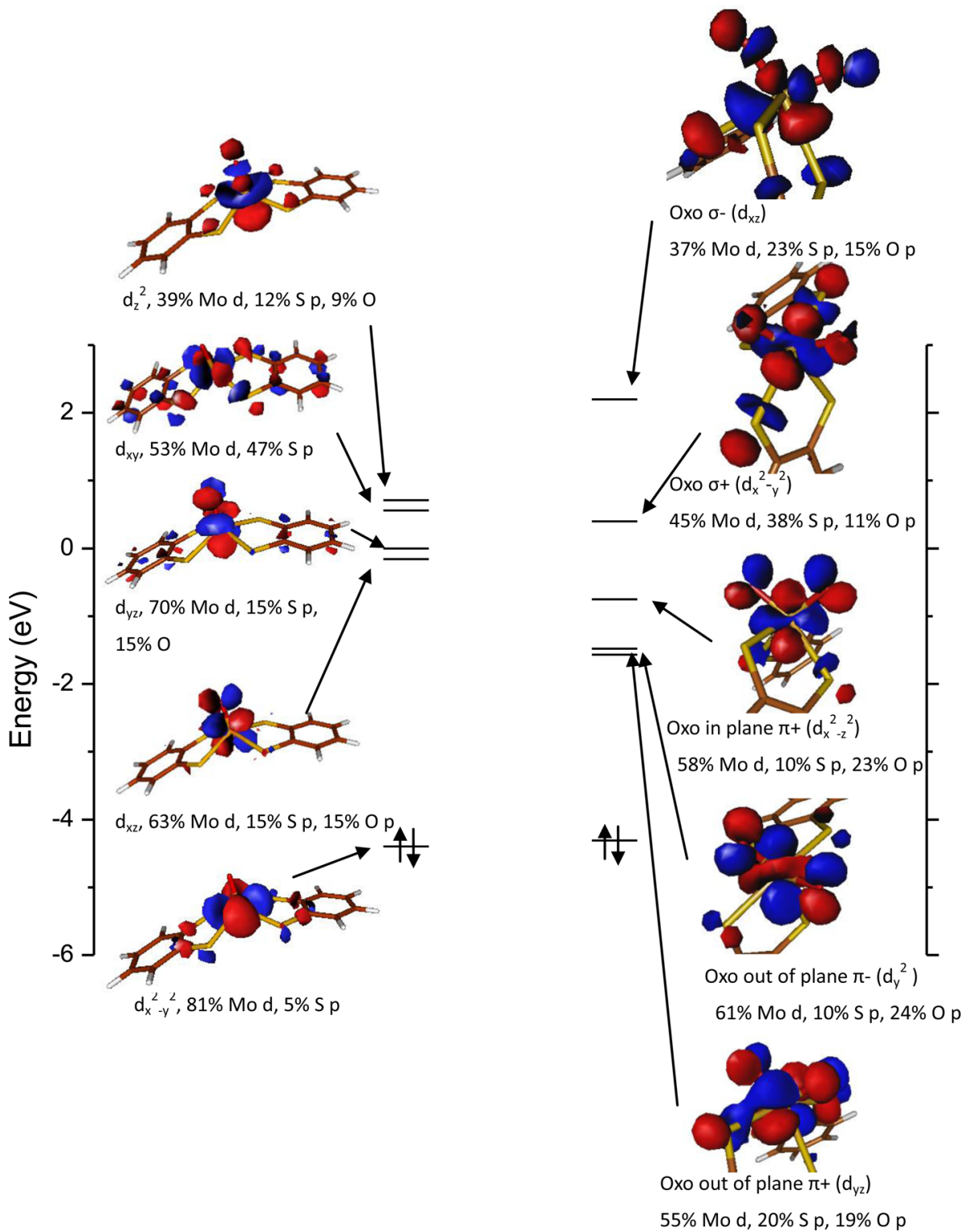

Figure 3. $\mathrm{MO}$ diagrams of $\left[\mathrm{Mo}^{\mathrm{IV}} \mathrm{O}(\mathrm{bdt})_{2}\right]^{2-}$ (left) and $\left[\mathrm{Mo}^{\mathrm{VI}} \mathrm{O}_{2}(\mathrm{bdt})_{2}\right]^{2-}$ (right). Selected atoms in $\left[\mathrm{Mo}^{\mathrm{VI}} \mathrm{O}_{2}(\mathrm{bdt})_{2}\right]^{2-}$ have been removed for clarity.

$\sim 2473.1 \mathrm{eV}$. There is also a low energy shoulder at $\sim 2472.4 \mathrm{eV}$. On the basis of the second derivative of the spectrum (Figure S1A), there is an additional peak at $2473.7 \mathrm{eV}$ below the rising edge. Compared to the spectrum of the $\left[\mathrm{Mo}^{\mathrm{IV}}(\mathrm{OSi})\right.$ $\left.(\mathrm{bdt})_{2}\right]^{-}$complex (Figure $2 \mathrm{~B}$ ), which requires a total of four peaks below the edge for a good fit, the three pre-edge features in the $\left[\mathrm{Mo}^{\mathrm{IV}} \mathrm{O}(\mathrm{bdt})_{2}\right]^{2-}$ complex are shifted to higher energy due to the presence of the strong oxo ligand, which destabilizes the energies of the unoccupied Mo d orbitals.

The $\left[\mathrm{Mo}^{\mathrm{VI}} \mathrm{O}_{2}(\mathrm{bdt})_{2}\right]^{2-}$ complex (Figure 2C) has a dominant feature at $\sim 2473.0 \mathrm{eV}$, and a clear pre-edge feature at $\sim 2471.2$ $\mathrm{eV}$. From the second derivative (Figure S1B), there are two 

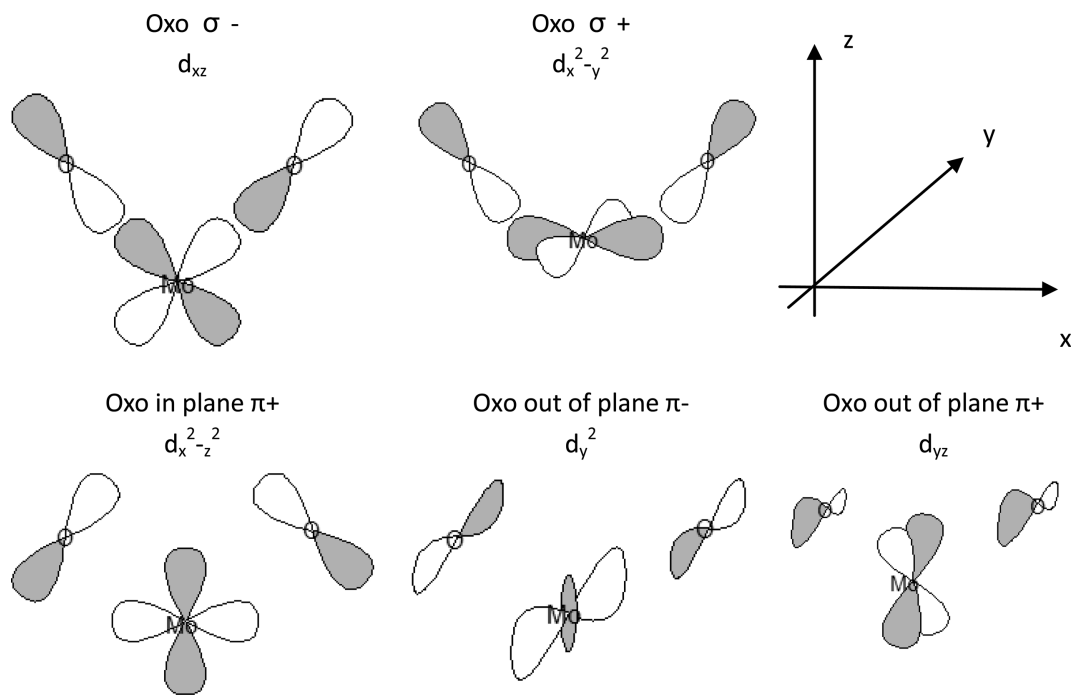

Figure 4. Symmetry adapted linear combinations (SALCs) of oxo $\mathrm{p} \pi$ and $\mathrm{p} \sigma$ orbitals and the d-orbital mixings in the antibonding MOs of bisoxo $\mathrm{Mo}^{\mathrm{VI}}$ bis-dithiolene complex. The coordinate system is given in the upper right panel.

additional peaks required at $\sim 2472.2$ and $\sim 2473.7 \mathrm{eV}$. Compared to the spectrum of the $\left[\mathrm{Mo}^{\mathrm{VI}} \mathrm{O}(\mathrm{OSi})(\mathrm{bdt})_{2}\right]^{-}$ complex (Figure 2D), which requires five peaks below the edge for a good fit, all four pre-edge features are again shifted to higher energy due to the additional oxo ligand in the bisoxo $\mathrm{Mo}^{\mathrm{VI}}$ complex.

In comparing the $\mathrm{Mo}^{\mathrm{VI}}$ to the $\mathrm{Mo}^{\mathrm{IV}}$ complexes, the pre-edge features for the $\left[\mathrm{Mo}^{\mathrm{VI}} \mathrm{O}_{2}(\mathrm{bdt})_{2}\right]^{2-}$ complex are at lower energy relative to those for the $\left[\mathrm{Mo}^{\mathrm{NV}} \mathrm{O}(\mathrm{bdt})_{2}\right]^{2-}$ complex. A similar low energy feature is also observed in the comparison of the $\left[\mathrm{Mo}^{\mathrm{VI}} \mathrm{O}(\mathrm{OSi})(\mathrm{bdt})_{2}\right]^{-}$and the $\left[\mathrm{Mo}^{\mathrm{IV}}(\mathrm{OSi})(\mathrm{bdt})_{2}\right]^{-}$complexes. The lower pre-edge energy for the $\mathrm{Mo}^{\mathrm{VI}}$ complexes is due to both the presence of an additional unoccupied d-orbital ( 2 spin holes) for the $\mathrm{Mo}^{\mathrm{VI}}$ relative to the $\mathrm{Mo}^{\mathrm{IV}}$ complexes, which corresponds to the lowest energy peak, and the increased $\mathrm{Z}_{\mathrm{eff}}$ of $\mathrm{Mo}^{\mathrm{VI}}$, which shifts the d-manifold down in energy.

The energies and intensities obtained from the fits are given in Table 1. Peak assignments are presented below.

3.1.2. DFT Correlations to XAS Spectra. Spin-unrestricted DFT calculations were used for peak assignments and for quantitative comparisons to the experimental data. The fully optimized geometric structures are consistent with the crystal structures which have bond distances within $0.04 \AA$, and bond angles within $3^{\circ}$ (Figure 1). ${ }^{39}$ Molecular orbital diagrams for the $\left[\mathrm{Mo}^{\mathrm{IV}} \mathrm{O}(\mathrm{bdt})_{2}\right]^{2-}$ and $\left[\mathrm{Mo}^{\mathrm{VI}} \mathrm{O}_{2}(\mathrm{bdt})_{2}\right]^{2-}$ complexes are presented in Figure 3. The MO contours for the reference compounds in Figure $1 \mathrm{~B}, \mathrm{D}$ are shown in Figure $\mathrm{S} 2$ for comparison.

In the five-coordinate, square pyramidal $\left[\mathrm{Mo}^{\mathrm{IV}} \mathrm{O}(\mathrm{bdt})_{2}\right]^{2-}$ complex, the Mo $\mathrm{d}_{x}{ }^{2}-{ }_{y}{ }^{2}$ orbital is predominantly nonbonding and is the HOMO ( $z$-axis along the Mo-oxo bond, and $x$-axis bisects the dithiolene ligands). There is a large HOMO/LUMO gap of $4.1 \mathrm{eV}$. The LUMO is close to the nearly degenerate Mo $\mathrm{d}_{x z} / y z$ set, which is strongly $\pi$-antibonding to both the oxo atom and dithiolene ligands (i.e., contains significant $S \mathrm{p}$ character), thus the low energy peak at $\sim 2472.5 \mathrm{eV}$ in Figure $2 \mathrm{~A}$ is assigned as the $\mathrm{S} 1 \mathrm{~s} \rightarrow \mathrm{Mo} \mathrm{d}_{x z} / y z$ transitions. The calculated total S 3p character in these two MOs is $31 \%$, while experimentally, the $S$ pre-edge intensity gives $38 \%$. The Mo $\mathrm{d}_{z}^{2}$ and Mo $\mathrm{d}_{x y}$ orbitals are $\sigma$ antibonding to the ligands and thus at higher energies. On the basis of the calculation shown in
Figure 3A, the $\sim 2473.3 \mathrm{eV}$ peak is assigned as the $\mathrm{S} 1 \mathrm{~s} \rightarrow$ Mo $\mathrm{d}_{x y} / \mathrm{d}_{z}^{2}$ transitions. The total $\mathrm{S} 3 \mathrm{p}$ covalency is $59 \%$ both experimentally and computationally. In the $\left[\mathrm{Mo}^{\mathrm{IV}}(\mathrm{OSi})\right.$ $\left.(\mathrm{bdt})_{2}\right]^{-}$reference complex, $\mathrm{d}_{z}{ }^{2}$ and $\mathrm{d}_{x y}$ are well separated in energy with the $d_{x y}$ at higher energy by $\sim 1 \mathrm{eV}$ (see figure S2). In the $\left[\mathrm{Mo}^{\mathrm{IV}} \mathrm{O}(\mathrm{bdt})_{2}\right]^{2-}$ complex, the $\mathrm{d}_{z}^{2}$ is shifted to higher energy, close to $d_{x y}$ due to the strong axial Mo-oxo bond. From our previous studies on the $\mathrm{Ni}$ and $\mathrm{Mo}$ bis-dithiolene complexes, the $\sim 2473.7 \mathrm{eV}$ peak in Figure $2 \mathrm{~A}$ is assigned as the $\mathrm{S} 1 \mathrm{~s} \rightarrow \mathrm{C}-\mathrm{S} \pi^{*} / \sigma^{*}$ intradithiolene ligand transitions. ${ }^{40,41}$

As shown in Figure 4, for the six-coordinate $\left[\mathrm{Mo}^{\mathrm{VI}} \mathrm{O}_{2}(\mathrm{bdt})_{2}\right]^{2-}$ complex, the $z$-axis is defined as bisecting the $\mathrm{O}-\mathrm{Mo}-\mathrm{O}$ angle, the $x$-axis is perpendicular to $z$ and in the $\mathrm{O}-\mathrm{Mo}-\mathrm{O}$ plane, and the $y$-axis is perpendicular to this plane. For this cis bisoxo Mo complex, the energies of the Mo dorbitals are dominated by their $\sigma / \pi$ bonding interactions with the two strong oxo donor ligands. The six $2 \mathrm{p}$-orbitals on the 2 oxo atoms form six combinations: the out of plane $\pi+$ and $\pi-$, in-plane $\pi+$ and $\pi-$, and $\sigma+, \sigma-; \pi$ indicates perpendicular to the $\mathrm{O}-\mathrm{Mo}-\mathrm{O}$ plane while $\sigma$ indicates along the bond, and the $+/-$ subscripts indicate the symmetric and antisymmetric combinations of the specific $\mathrm{O} 2$ p-orbitals. The in-plane $\pi-$ is nonbonding. The out-of-plane $\pi+$ and $\pi-$, and in-plane $\pi+$ interact with the $\mathrm{d} \pi$ orbitals on Mo, with the in-plane $\pi+$ interaction being the strongest due to its increased overlap with the Mo $\left(\mathrm{d}_{x}^{2}-{ }_{z}^{2}\right)$ (see Figure 3). Thus, the low energy peak at $\sim 2471.2 \mathrm{eV}$ in Figure 2C is assigned as the combined set of transitions from the $S 1 s \rightarrow$ Mo d $_{y z}$ (that interacts with the outof-plane oxo $\pi+$ ) and the $\mathrm{S} 1 \mathrm{~s} \rightarrow \mathrm{Mo}\left(\mathrm{d}_{y}{ }^{2}\right)$ (that interacts with the out-of-plane oxo $\pi-$ ). Experiment gives $33 \% \mathrm{~S}$ p character, while the DFT calculation has a total of $31 \% \mathrm{~S} 3 \mathrm{p}$ character in these two transitions. The peak at $2472.2 \mathrm{eV}$, which is $\sim 1 \mathrm{eV}$ to higher energy, is assigned as $\mathrm{S} 1 \mathrm{~s} \rightarrow \mathrm{Mo}\left(\mathrm{d}_{x}^{2}-z_{z}^{2}\right)$ (that interacts with in-plane oxo $\pi+)$ transition. Experimentally, this transition has $15 \%$ S 3 p character, while the calculation gives $10 \%$.

The MOs with oxo $\sigma$ character are strongly antibonding and thus at higher energy. The $\sim 2473.0 \mathrm{eV}$ peak is assigned as the $\mathrm{S}$ $1 \mathrm{~s} \rightarrow \mathrm{Mo}\left(\mathrm{d}_{x}^{2}-\mathrm{d}_{y}^{2}\right)$ (antibonding with oxo atoms $\sigma+$ ). The $\mathrm{S}$ covalency is $53 \%$ from calculation vs $38 \%$ from experiment. The $\mathrm{S} 1 \mathrm{~s} \rightarrow \operatorname{Mo}\left(\mathrm{d}_{x z}\right)$ (antibonding with oxo atoms $\sigma-$ ) transition is calculated to be $\sim 3.8 \mathrm{eV}$ above the LUMO, 
overlapping the rising edge and thus could not be experimentally resolved. Computationally, this transition has $23 \% \mathrm{~S}$ p character. Finally, on the basis of our previous studies, the $\sim 2473.6 \mathrm{eV}$ peak is assigned as $\mathrm{S} 1 \mathrm{~s} \rightarrow \mathrm{C}-\mathrm{S} \pi^{*} / \sigma^{*}$ intradithiolene ligand transitions.

Comparisons of the DFT calculations with S K-edge XAS experimental data show that the calculations reproduce the preedge transition energy splittings, but somewhat underestimate the $S$ covalency (Table 1). However, these DFT calculations did well in reproducing the experimental energies and intensities in the lower energy region. As the low-energy unoccupied MOs are the frontier molecular orbitals (FMO) in the oxo transfer reaction, these DFT calculations will be used to further evaluate the reaction coordinate for oxo transfer to phosphite ester (Section 3.3).

In comparing the $\left[\mathrm{Mo}^{\mathrm{IV}} \mathrm{O}(\mathrm{bdt})_{2}\right]^{2-}$ to the $\left[\mathrm{Mo}^{\mathrm{VI}} \mathrm{O}_{2}(\mathrm{bdt})_{2}\right]^{2-}$ complexes, the total $\mathrm{S}$ experimental covalency changes from $194 \%$ to $248 \%$, an increase of $54 \%$, (computationally $180 \%$ to $204 \%$, an increase of $24 \%$ ). This increase is much smaller than the increase observed for the tris-dithiolene $\mathrm{Mo}^{\mathrm{IV}}$ and $\mathrm{Mo}^{\mathrm{VI}}$ complexes $^{40}$ (118\%), which undergo a ligand-based redox process (i.e., noninnocent behavior). Thus, for the monooxo $\mathrm{Mo}^{\mathrm{IV}}$ and bisoxo $\mathrm{Mo}^{\mathrm{VI}}$ complexes, the presence of oxo ligands leads to innocent behavior of the dithiolenes where the covalent donor bonding to the Mo simply increases upon oxidation of the metal center.

3.2. Oxo Bond Strengths. The DFT calculations were further used to estimate the $\mathrm{Mo}^{\mathrm{VI}}$-oxo bond strengths in the bisoxo and monooxo complexes and to compare to experimental values where available. These values are necessary for consideration of the reaction coordinate results in the next section.

For the oxo transfer reaction: $\mathrm{X}+1 / 2 \mathrm{O}_{2} \rightarrow \mathrm{XO}$, the $\mathrm{X}=\mathrm{O}$ bond strength is the difference between one-half the $\mathrm{O}_{2}$ bond strength and the $\Delta H$ of the reaction. The $\Delta H^{\mathrm{rxn}}$ values were obtained from the DFT calculations, using $119 \mathrm{kcal} / \mathrm{mol}$ for the value of the $\mathrm{O}_{2}$ bond strength. ${ }^{42-44}$ These oxo bond strengths are given in Table 2 . The computational results are within 7 $\mathrm{kcal} / \mathrm{mol}$ of the experimental values, where available. ${ }^{42-45}$

The Mo-oxo bond strength in $\left[\mathrm{Mo}^{\mathrm{VI}} \mathrm{O}_{2}(\mathrm{bdt})_{2}\right]^{2-}$ is $\sim 104$ $\mathrm{kcal} / \mathrm{mol}$, while that in $\left[\mathrm{Mo}{ }^{\mathrm{VI}} \mathrm{O}(\mathrm{OSi})(\mathrm{bdt})_{2}\right]^{-}$is $\sim 118 \mathrm{kcal} /$ mol. Thus, the monooxo compound has a $14 \mathrm{kcal} / \mathrm{mol}$ stronger Mo-oxo bond, out of $\sim 118 \mathrm{kcal} / \mathrm{mol}$. From the energy diagram in Figure 3, the $\mathrm{Mo}^{\mathrm{IV}}$-oxo bond order in the monooxo complex is 3 , which will remain the same in the $\mathrm{Mo}^{\mathrm{VI}}$ monooxo complex (i.e., 2 electrons are lost from the nonbonding $\mathrm{d}_{x y}$ orbital), while the $\mathrm{Mo}-$ oxo bond order in the $\mathrm{Mo}^{\mathrm{VI}}$ bisoxo complex is 2.5 per bond. On breaking the $\mathrm{Mo-}$-oxo bond in the monooxo complex, the bond order of 3 is lost. Alternatively, breaking one Mo-oxo bond in the bisoxo complex generates a monooxo product which has a Mo-oxo bond order of 3; thus, the bond order only decreases by 2 . This reflects the spectrator oxo effect described by Rappe and Goddard. ${ }^{46}$

This $\sim 10 \%$ decrease in bond strength can be considered quantitatively in terms of the Mayer bond orders $(\mathrm{MBO})^{47}$ acquired from the DFT calculations. In the $\left[\mathrm{Mo}^{\mathrm{VI}} \mathrm{O}_{2}(\mathrm{bdt})_{2}\right]^{2-}$ compound, the MBO for each Mo-oxo bond is 1.81 , and in the $\left[\mathrm{Mo}^{\mathrm{IV}} \mathrm{O}(\mathrm{bdt})_{2}\right]^{2-}$ compound, the Mo-oxo $\mathrm{MBO}$ is 1.99 . Loss of one oxo ligand from the $\left[\mathrm{Mo}^{\mathrm{VI}} \mathrm{O}_{2}(\mathrm{bdt})_{2}\right]^{2-}$ complex to produce the $\left[\mathrm{Mo}^{\mathrm{IV}} \mathrm{O}(\mathrm{bdt})_{2}\right]^{2-}$ complex eliminates a $\mathrm{MBO}$ contribution of 1.81 , while the remaining spectator Mo-oxo $\mathrm{MBO}$ increases from 1.81 to 1.99 ; thus, the total Mo-oxo $\mathrm{MBO}$ lost is $1.63(1.99-1.81 \times 2)$. In the $\left[\mathrm{Mo}^{\mathrm{VI}} \mathrm{O}(\mathrm{OSi})\right.$ -
Table 2. Comparative Experimental and Computational Oxo Bond Energies

\begin{tabular}{|c|c|c|c|}
\hline compound & oxo bond & $\begin{array}{l}\text { experimental } \\
\text { bond strength } \\
(\mathrm{kcal} / \mathrm{mol})\end{array}$ & $\begin{array}{l}\text { computational } \\
\text { bond strength } \\
(\mathrm{kcal} / \mathrm{mol})^{a}\end{array}$ \\
\hline $\mathrm{O}_{2}$ & $\mathrm{O}=\mathrm{O}$ & 119 & - \\
\hline DMSO & $\mathrm{S}=\mathrm{O}$ & 87 & 91 \\
\hline $\mathrm{O}=\mathrm{P}(\mathrm{Me})_{3}$ & $\mathrm{P}=\mathrm{O}$ & 139 & 144 \\
\hline $\mathrm{O}=\mathrm{P}(\mathrm{Pr})_{3}$ & $\mathrm{P}=\mathrm{O}$ & 138 & 144 \\
\hline $\mathrm{O}=\mathrm{P}(\mathrm{Bu})_{3}$ & $\mathrm{P}=\mathrm{O}$ & 137 & 144 \\
\hline $\mathrm{O}=\mathrm{P}(\mathrm{OMe})_{3}$ & $\mathrm{P}=\mathrm{O}$ & & 151 \\
\hline $\mathrm{O}=\mathrm{P}(\mathrm{OEt})_{3}$ & $\mathrm{P}=\mathrm{O}$ & 150 & 151 \\
\hline $\mathrm{SO}_{4}^{2-}$ & $\mathrm{S}=\mathrm{O}$ & & 146 \\
\hline $\mathrm{HSO}_{4}^{-}$ & $\mathrm{S}=\mathrm{O}$ & 123 & 122 \\
\hline $\mathrm{H}_{2} \mathrm{SO}_{4}$ & $S=O$ & & 107 \\
\hline$\left[\mathrm{Mo}^{\mathrm{VI}} \mathrm{O}_{2}(\mathrm{bdt})_{2}\right]^{2-}$ & $\mathrm{Mo}=\mathrm{O}$ & & 104 \\
\hline$\left[\mathrm{Mo}^{\mathrm{VI}} \mathrm{O}_{2}(\mathrm{mdt})_{2}\right]^{2-}$ & $\mathrm{Mo}=\mathrm{O}$ & & 106 \\
\hline$\left[\mathrm{Mo}^{\mathrm{VI}} \mathrm{O}_{2}(\mathrm{mnt})_{2}\right]^{2-}$ & $\mathrm{Mo}=\mathrm{O}$ & & 102 \\
\hline$\left[\mathrm{Mo}^{\mathrm{VI}} \mathrm{O}(\mathrm{OMe})(\mathrm{bdt})_{2}\right]^{-}$ & $\mathrm{Mo}=\mathrm{O}$ & & 116 \\
\hline$\left[\mathrm{Mo}^{\mathrm{VI}} \mathrm{O}(\mathrm{OSi})(\mathrm{bdt})_{2}\right]^{-}$ & $\mathrm{Mo}=\mathrm{O}$ & & 118 \\
\hline$\left[\mathrm{Mo}^{\mathrm{VI}} \mathrm{O}_{2}(\mathrm{mnt})(\mathrm{SMe})\right]^{-}$ & $\mathrm{Mo}=\mathrm{O}$ & & 126 \\
\hline
\end{tabular}

${ }^{a}$ DFT calculations were carried out in Gaussian 09, using B3LYP functional, SDD basis set for Mo, 6-311G(d) for S, O, N and P, and 6$311 \mathrm{G}(\mathrm{d})$ for other atoms.

(bdt $\left.)_{2}\right]^{-}$compound, the Mo-oxo MBO is 1.86 and in going to $\left[\mathrm{Mo}^{\mathrm{IV}}(\mathrm{OSi})(\mathrm{bdt})_{2}\right]^{-}$, this $\mathrm{MBO}$ is lost. The $\sim 13 \%$ decrease in Mo-oxo MBO lost in going from the bis- to monooxo, relative to mono- to desoxo conversion (both involving changing from a six-coordinate $\mathrm{Mo}^{\mathrm{VI}}$ to a five-coordinate $\mathrm{Mo}^{\mathrm{IV}}$ ), is consistent with the $\sim 10 \%$ Mo-oxo bond strength decrease, and reflects the effect of the spectator oxo in the bisoxo complex and its change in going to the monooxo $\mathrm{Mo}^{\mathrm{IV}}$ complex.

3.3. Reaction Coordinates for Oxo Transfer. 3.3.1. Transfer to Phosphite Ester. In this section, we evaluate the oxo transfer process computationally using the Mo complexes with mnt ligands instead of bdt, because detailed kinetic data are available for oxo transfer from the $\left[\mathrm{Mo}^{\mathrm{VI}} \mathrm{O}_{2}(\mathrm{mnt})_{2}\right]^{2-}$ complex to $\mathrm{P}(\mathrm{OR})_{3} \cdot{ }^{23}$ As described in Table S2, the geometric and electronic structures of the $\left[\mathrm{Mo}^{\mathrm{VI}} \mathrm{O}_{2}(\mathrm{mnt})_{2}\right]^{2-}$ and $\left[\mathrm{Mo}^{\mathrm{IV}} \mathrm{O}(\mathrm{mnt})_{2}\right]^{2-}$ complexes are very similar to those of the analogous bdt ligand complexes studied above.

For the oxo transfer reaction:

$$
\begin{aligned}
& {\left[\mathrm{Mo}^{\mathrm{VI}} \mathrm{O}_{2}(\mathrm{mnt})_{2}\right]^{2-}+\mathrm{P}(\mathrm{OMe})_{3}} \\
& \quad \rightarrow\left[\mathrm{Mo}^{\mathrm{IV}} \mathrm{O}(\mathrm{mnt})_{2}\right]^{2-}+\mathrm{O}=\mathrm{P}(\mathrm{OMe})_{3}
\end{aligned}
$$

the calculated $\Delta H^{\mathrm{rxn}}$ is $-49 \mathrm{kcal} / \mathrm{mol}$ (Figure $5 \mathrm{~A}, \mathrm{R} \rightarrow \mathrm{P}$ ), which reflects the difference in the $\mathrm{X}=\mathrm{O}$ bond strengths of $\left[\mathrm{Mo}^{\mathrm{VI}} \mathrm{O}_{2}(\mathrm{mnt})_{2}\right]^{2-}$ and $\mathrm{O}=\mathrm{P}(\mathrm{OMe})_{3}(151-102 \mathrm{kcal} / \mathrm{mol}$, Table 2).

Three possible transition states were found for reaction 1 (Figure 5A). Each transition state structure in Figure 5A has only one imaginary frequency, and has an intrinsic reaction coordinate (IRC, a one-dimensional path along the potential energy curve of a chemical reaction which describes the path of least resistance between reactants and products) coupling it to both the reactant and product. TS1 has the phosphite ester $\mathrm{P}$ bonding to one of the terminal oxo atoms. It is very similar to that described elsewhere. ${ }^{48}$ TS2 has the phosphorus atom bound to both oxo atoms to form a bis ( $\mu$-oxo) structure. TS3 is similar to TS1, but with a different $\mathrm{P}-\mathrm{O}$ orientation, such that 


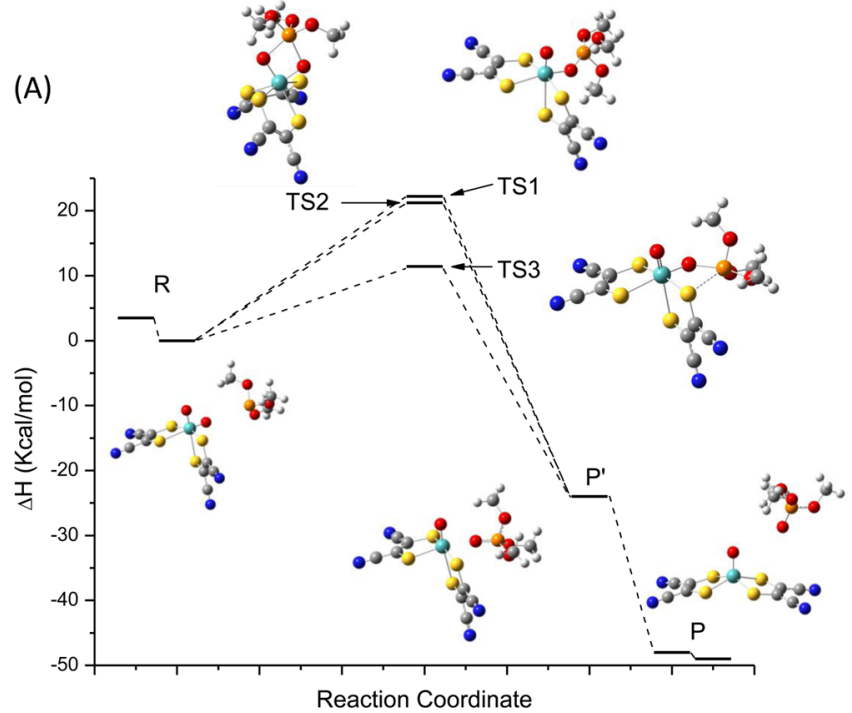

(B)
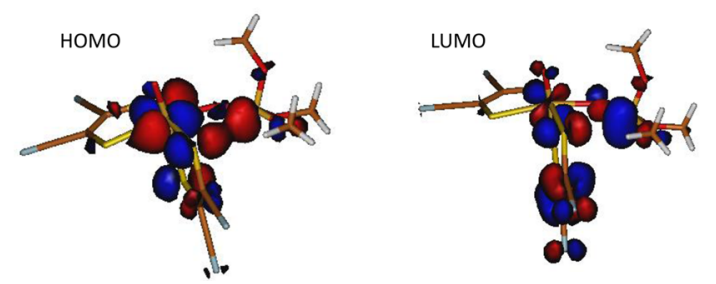

Figure 5. (A) Geometric structures and enthalpies at different stages of the reaction coordinate of (1). R for Reactant, TS for Transition State, $\mathrm{P}^{\prime}$ for the state on the path way that the oxo has been transferred while the product is still bound, $\mathrm{P}$ for Product. (B) HOMO (left) and LUMO (right) around TS3, showing the bonding/antibonding interaction between the phosphorus lone pair and $\mathrm{d} \pi$ oxo as well as one of the dithiolene sulfurs.

the phosphorus atom also interacts with one of the sulfurs of a dithiolene ligand. The $\mathrm{P}-\mathrm{O}$ orientation in TS3 is similar to a known structure, ${ }^{18}$ but the compound in that study does not have delocalized dithiolene ligation. TS3 has the lowest energy barrier $(12 \mathrm{kcal} / \mathrm{mol}$; TS1 has 21 and TS2 has $20 \mathrm{kcal} / \mathrm{mol})$, which is very similar to the $\Delta H^{\ddagger}$ that was measured experimentally $(10 \mathrm{kcal} / \mathrm{mol}){ }^{23}$

There are two major points to note about the geometric and electronic structures of these transition states. First, TS3 has a $\mathrm{P}-\mathrm{S}$ interaction involving the phosphorus lone pair donating electron density into the Mo-based unoccupied d-orbital that is delocalized onto the oxo and the $S \mathrm{p}$ orbital that is perpendicular to the dithiolene plane (Figure 5B). The $\mathrm{P}-\mathrm{S}$ distance is $\sim 3.3 \AA$ and the $\mathrm{P}-\mathrm{S} \mathrm{MBO}$ is 0.15 . This $\mathrm{P}-\mathrm{S}$ interaction stabilizes the transition state by $\sim 10 \mathrm{kcal} / \mathrm{mol}$ relative to TS1, which has the $\mathrm{P}$ lone pair interact only with the oxo $\mathrm{p} \pi$ orbital. Second, one of the $\mathrm{O}(\mathrm{Me})-\mathrm{P}-\mathrm{O}(\mathrm{Mo})$ angles in TS3 (and TS1) is almost linear $\left(\sim 165^{\circ}\right)$. This was first noted by Hall and colleagues, ${ }^{18}$ and attributed to a nucleophilic attack of the occupied oxo $\mathrm{p}$ orbital on the $\sigma^{*}$ orbital of the phosphite ester. From a fragment analysis, at the transition state, there is about $\sim 1.5 \%$ phosphite ester $\sigma^{*}$ character mixed into the occupied valence orbitals. This mixing is only observed around the transition state, and can be eliminated by decreasing the $\mathrm{O}(\mathrm{Me})-\mathrm{P}-\mathrm{O}(\mathrm{Mo})$ angle. This results in an $\sim 4 \mathrm{kcal} / \mathrm{mol}$ energy penalty. Alternatively, there is $\sim 17 \%$ of the phosphite ester lone pair orbital mixed into the unoccupied valence $d$ orbital at the transition state (Figure 5B LUMO). Thus, the electron transfer accompanying the oxo transfer process is mainly the phosphorus lone pair into the empty Mo $\mathrm{d} \pi$ orbital through the oxo bridge.

At TS3 in Figure 5A, the Mo-O distance is $1.83 \AA$ and the $\mathrm{P}-\mathrm{O}$ distance is $1.99 \AA$, while the $\mathrm{Mo}-\mathrm{O}$ distance for the $\left[\mathrm{Mo}^{\mathrm{VI}} \mathrm{O}_{2}(\mathrm{mnt})_{2}\right]^{2-}$ reactant is $1.72 \AA$, and the $\mathrm{P}-\mathrm{O}$ distance for the $\mathrm{O}=\mathrm{P}(\mathrm{OMe})_{3}$ product is $1.48 \AA$. Thus, the Pauling bond fraction $^{49}$ for the $\mathrm{Mo}-\mathrm{O}$ bond is 1.43 (decreased from 2.11), and that of the $\mathrm{P}-\mathrm{O}$ bond is 0.33 . Figure $6 \mathrm{~A}$ gives this in terms
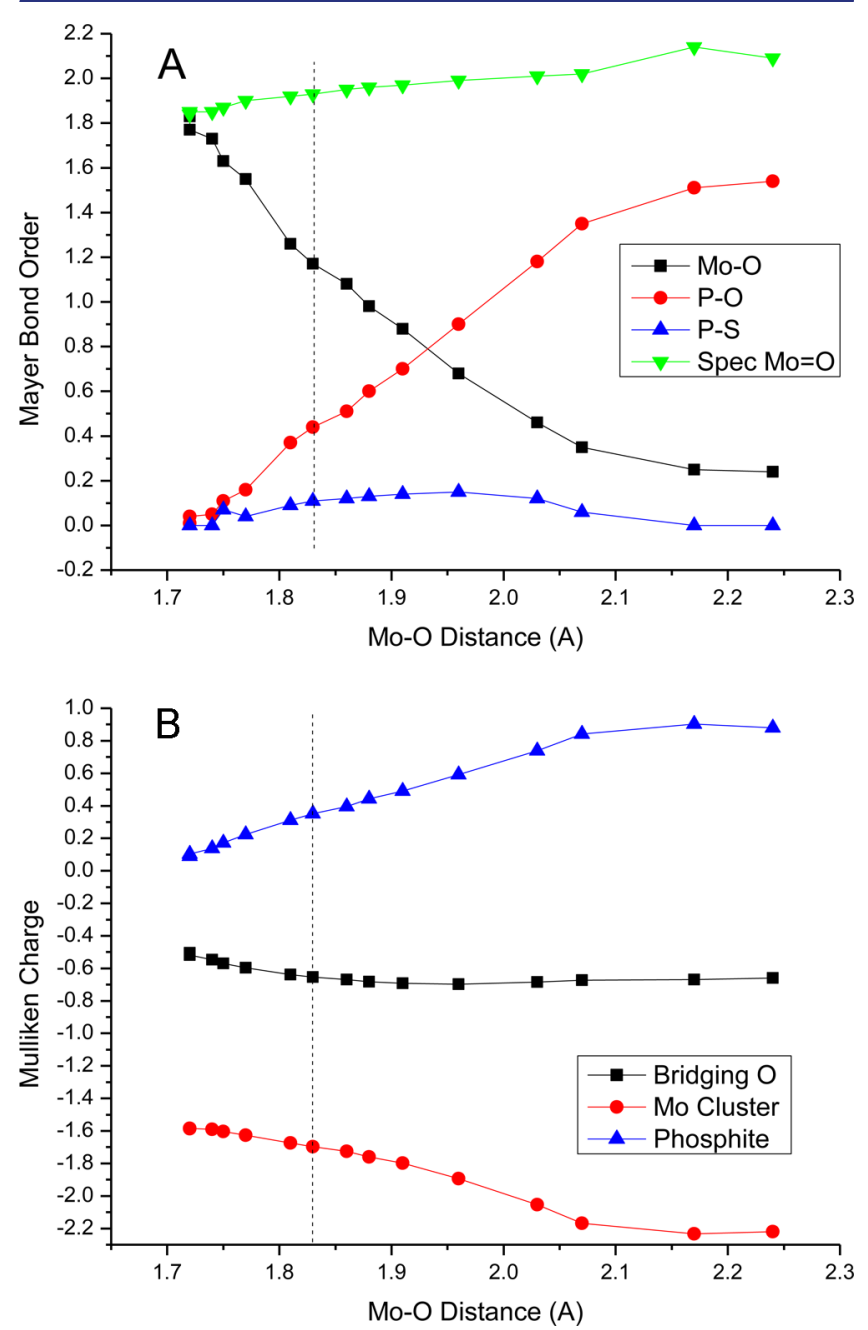

Figure 6. Mayer bond order (MBO) (A) and Mulliken charge change (B) for reaction 1 along the reaction coordinate in terms of $\mathrm{Mo}-\mathrm{O}$ distance. Spec $\mathrm{Mo}=\mathrm{O}$ indicating the spectator oxo in $\left[\mathrm{Mo}^{\mathrm{VI}} \mathrm{O}_{2}(\mathrm{mnt})_{2}\right]^{2-}$, which is the oxo atom that is not transferred. The dashed line indicates the distance in TS3.

of Mayer bond orders at the transition state: $\sim 1 / 3$ of the Mo$\mathrm{O}$ bond order is lost (a decrease in $\mathrm{MBO}$ from 1.84 to 1.17 ) and $\sim 1 / 4$ of the $\mathrm{P}-\mathrm{O}$ bond is formed (an increase from 0.00 to 0.43 ; the $\mathrm{MBO}$ for the $\mathrm{P}=\mathrm{O}$ bond in the product is 1.80 ). Figure $6 \mathrm{~B}$ shows that about $1 / 3$ of the charge has been transferred from the substrate to the Mo complex at this transition state. The above results indicate that this oxo transfer reaction has an early transition state, with only $0.1 \AA$ of $\mathrm{Mo}-\mathrm{O}$ bond elongation.

The calculations show that there is not much structural rearrangement of the dithiolenes and the spectator oxo atom in this oxo transfer reaction. When this oxo transfer is complete, 
but with the phosphate ester product still bound $\left(\mathrm{P}^{\prime}\right.$ in Figure $5 \mathrm{~A}$, which was obtained from a point on the IRC toward the product with a $\mathrm{Mo}-\mathrm{O}$ (phosphite ester) bond distance of 2.24 $\AA$ ), the two dithiolene planes remain perpendicular to each other, as in R and TS3. However, $\mathrm{P}^{\prime}$ is not a local minimum, and the product is lost along the reaction coordinate to give the monooxo $\mathrm{Mo}^{\mathrm{IV}}$ complex. As the phosphate ester comes off, the two dithiolenes rotate into the same plane to form $\mathrm{P}$ (Figure $5 \mathrm{~A}$ ), and the enthalpy is lowered by $25 \mathrm{kcal} / \mathrm{mol}$ from $\mathrm{P}^{\prime}$ to $\mathrm{P}$. This is in contrast to the reaction coordinate in refs 18 and 20, where the product remained bound. This difference reflects the fact that the final product in reaction 1 is a five-coordinate $\left[\mathrm{Mo}^{\mathrm{IV}} \mathrm{O}(\mathrm{mnt})_{2}\right]^{2-}$ complex that has its two dithiolenes coplanar. The four $S \mathrm{p} \pi$ orbitals that are perpendicular to the dithiolene planes are parallel with each other, and this stabilizes the square pyramidal five-coordinate Mo monooxo complex.

3.3.2. Transfer to Sulfite. Sarkar et al. found that the $\left[\mathrm{Mo}^{\mathrm{VI}} \mathrm{O}_{2}(\mathrm{mnt})_{2}\right]^{2-}$ complex can also transfer an oxo atom to bisulfite, ${ }^{17}$ which is the native substrate of sulfite oxidase, to form bisulfate. They showed that the reaction

$$
\begin{aligned}
& {\left[\mathrm{Mo}^{\mathrm{VI}} \mathrm{O}_{2}(\mathrm{mnt})_{2}\right]^{2-}+\mathrm{HSO}_{3}^{-}} \\
& \quad \rightarrow\left[\mathrm{Mo}^{\mathrm{IV}} \mathrm{O}(\mathrm{mnt})_{2}\right]^{2-}+\mathrm{HSO}_{4}^{-}
\end{aligned}
$$

exhibits Michaelis-Menten kinetics. However, the proposed transition state has an oxo atom of the substrate bound to the Mo to form a seven-coordinate structure, and is too high in energy $(36 \mathrm{kcal} / \mathrm{mol})$ for reaction 2 to occur based on kinetic data. ${ }^{50}$ It is also not on the IRC. A lower energy transition state was thus found, and determined to be on the IRC to both the reactant and the product. This transition state is very similar to TS3 in Figure 5A with the sulfur atom of $\mathrm{HSO}_{3}{ }^{-}$bound to one of the terminal oxo atoms (Figure S3).

Note that an ES precursor complex is obtained from the IRC (Figure S3) that has the $\mathrm{HSO}_{3}^{-}$anion bound to the $\left[\mathrm{Mo}^{\mathrm{VI}} \mathrm{O}_{2}(\mathrm{mnt})_{2}\right]^{2-}$ complex through an $\mathrm{H}$-bond to one of the dithiolene sulfurs. This is consistent with the observation that reaction 2 with a monoprotonated sulfite exhibits Michaelis-Menten kinetics, while reaction 1 with phosphite ester is second-order.

The calculated $\Delta H^{\ddagger}$ for reaction 2 is $23 \mathrm{kcal} / \mathrm{mol}$, and the intrinsic barrier (obtained by using the Marcus equation ${ }^{51,52}$ to eliminate the effect of the thermodynamic driving force) is 32 $\mathrm{kcal} / \mathrm{mol}$. This is similar to the intrinsic barrier of reaction 1 ( $28 \mathrm{kcal} / \mathrm{mol})$; thus, the difference in barrier heights between reactions 1 and 2 simply reflects the difference between the $\mathrm{X}=\mathrm{O}$ bond strengths in the product $(151 \mathrm{kcal} / \mathrm{mol}$ for phosphate ester vs $122 \mathrm{kcal} / \mathrm{mol}$ for bisulfate).

A second-order rate constant for reaction 2 (at low substrate concentration, before saturation) of $\sim 60 \mathrm{M}^{-1} \mathrm{~s}^{-1}$ has been reported. ${ }^{17}$ This value is 3 orders of magnitude faster than that observed for reaction 1 at the same temperature $\left(1.7 \times 10^{-2}\right.$ $\mathrm{M}^{-1} \mathrm{~s}^{-1}$ ), which is not consistent with the difference in the product bond strengths. Reaction 2 was performed at $\mathrm{pH} \sim 5$ (the Mo compound is not stable under basic conditions). At $\mathrm{pH} \mathrm{5,} \mathrm{the} \mathrm{reactant} \mathrm{is} \mathrm{monoprotonated} \mathrm{HSO}_{3}{ }^{-}\left(\mathrm{p} K_{\mathrm{a}}=7.2\right)$; however, the product should be deprotonated $\mathrm{SO}_{4}{ }^{2-}\left(\mathrm{p} K_{\mathrm{a}}=\right.$ 1.9). Thus, the reaction measured experimentally is

$$
\begin{aligned}
& {\left[\mathrm{Mo}^{\mathrm{VI}} \mathrm{O}_{2}(\mathrm{mnt})_{2}\right]^{2-}+\mathrm{HSO}_{3}{ }^{-}+\text {Base }} \\
& \quad \rightarrow\left[\mathrm{Mo}^{\mathrm{IV}} \mathrm{O}(\mathrm{mnt})_{2}\right]^{2-}+\mathrm{SO}_{4}{ }^{2-}+\text { HBase }
\end{aligned}
$$

Thermodynamically, the $\mathrm{S}=\mathrm{O}$ bond in $\mathrm{SO}_{4}{ }^{2-}$ is $\sim 20 \mathrm{kcal} /$ mol stronger than that in $\mathrm{HSO}_{4}^{-}$; thus, the free energy for the formation of $\mathrm{SO}_{4}{ }^{2-}$ is larger. Computationally, the $\Delta G^{\ddagger}$ for reaction 2 is $27 \mathrm{kcal} / \mathrm{mol}$, and the $\Delta G^{\ddagger}$ for the reaction $\left[\mathrm{Mo}^{\mathrm{VI}} \mathrm{O}_{2}(\mathrm{mnt})_{2}\right]^{2-}+\mathrm{SO}_{3}{ }^{2-} \rightarrow\left[\mathrm{Mo}^{\mathrm{IV}} \mathrm{O}(\mathrm{mnt})_{2}\right]^{2-}+\mathrm{SO}_{4}{ }^{2-}$ is 3 $\mathrm{kcal} / \mathrm{mol}$. Experimentally, the $\Delta G^{\ddagger}$ for reaction 3 is $\sim 13 \mathrm{kcal} /$ mol based on the kinetics data $\left(1.7 \times 10^{-2} \mathrm{M}^{-1} \mathrm{~s}^{-1}\right.$ at $298 \mathrm{~K}$ at low concentration).

The conjugate base of propionic acid was used to model the protonation behavior of bisulfite and sulfate in solution, such that bisulfite remain monoprotonated and sulfate is totally deprotonated. This was included next to the Mo complex as a base and the reaction coordinate with $\mathrm{HSO}_{3}{ }^{-}$was calculated as given in Figure 7.

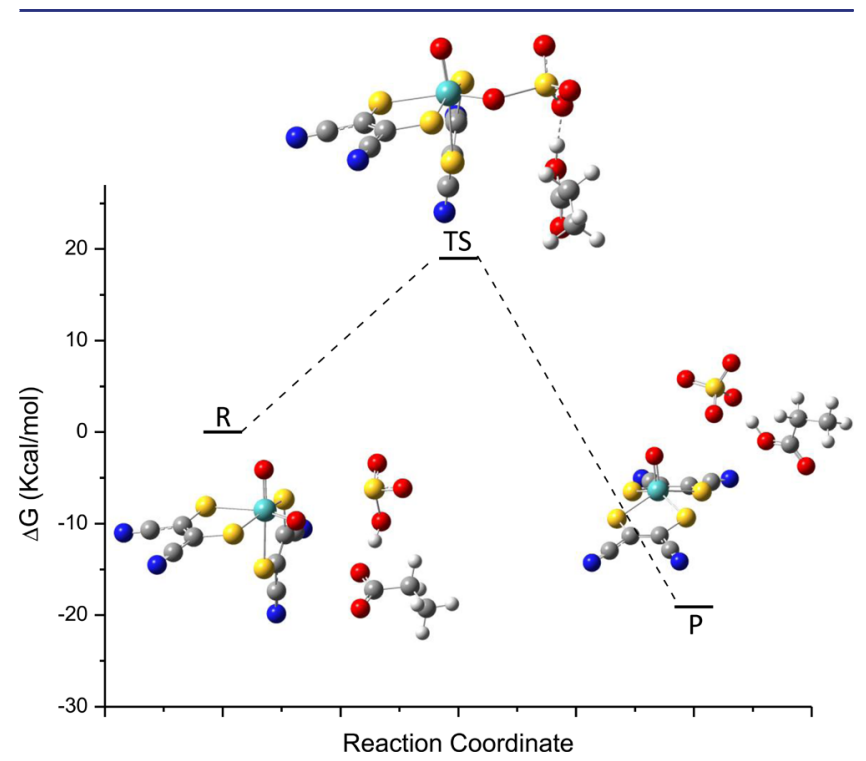

Figure 7. Reaction coordinate of reaction 3 . The conjugate base of propionic acid was used to model the protonation behavior of bisulfite and sulfate in solution.

The substrate $\mathrm{HSO}_{3}{ }^{-}$is almost deprotonated at the transition state, with an $\mathrm{O}-\mathrm{H} \mathrm{MBO}$ of 0.16 to the substrate, and 0.59 to the base. The calculated $\Delta G^{\ddagger}$ for this reaction is 19 $\mathrm{kcal} / \mathrm{mol}$, which is reasonably consistent with experimental data. Thus, loss of the proton from the substrate occurs at an early stage and facilitates the oxo transfer reaction to sulfite.

\section{DISCUSSION}

4.1. Nature of the Oxo Transfer Reaction to Phosphite Ester. The S K-edge XAS and DFT results show that the transformation from $\left[\mathrm{Mo}^{\mathrm{VI}} \mathrm{O}_{2}(\mathrm{bdt})_{2}\right]^{2-}$ to $\left[\mathrm{Mo}^{\mathrm{IV}} \mathrm{O}(\mathrm{bdt})_{2}\right]^{2-}$ involves a metal-based redox process; thus, the dithiolenes act as innocent covalent ligands in the oxo transfer reaction. It is initiated by the phosphorus lone pair attack on an unoccupied metal-based $\mathrm{d} \pi$-orbital that contains oxygen $\mathrm{p} \pi$ character, which leads to the formation of the $\mathrm{P}-\mathrm{O}$ bond and loss of the Mooxo bond. The almost linear $\mathrm{R}-\mathrm{P}-\mathrm{O}$ bond angle $\mathrm{e}^{18}$ and a $\mathrm{P}-\mathrm{S}$ interaction between the phosphite and a dithiolene ligand (see Figure 5) help stabilize the TS structure. On the basis of Mulliken charges and Mayer bond orders (Figure 6), about 1/3 of the oxo bond from the Mo and the electron pair from the phosphite ester are transferred at the TS, while the Mo-O bond has only been elongated by $0.1 \AA$. The two dithiolene planes remain almost perpendicular throughout the oxo transfer 
process, and subsequently, there is an additional $\sim 25 \mathrm{kcal} / \mathrm{mol}$ driving force for the two dithiolenes to reorient into the fivecoordinate square pyramidal monooxo $\mathrm{Mo}^{\mathrm{IV}}$ product where the dithiolenes are now coplanar and the product is released (Figure 5A). The $\sim 25 \mathrm{kcal} / \mathrm{mol}$ driving force is consistent with the fact that the phosphate ester product does not remain bound to the $\mathrm{Mo}^{\mathrm{IV}} \mathrm{O}$ bis-dithiolene complex, in contrast to nondithiolene Mo systems where the product remains bound after oxo transfer.

4.2. Comparison of Oxo Transfer from a Metal-Oxo to Substrate versus Oxo Transfer from a Substrate Oxo to Metal lon. From a comparison to our previous study, ${ }^{53}$ there is a major difference in the TS for oxo transfer from substrates to desoxo $\mathrm{Mo}^{\mathrm{IV}}$ complexes, relative to oxo transfer from bisoxo $\mathrm{Mo}^{\mathrm{VI}}$ complexes to substrates. In the former, the electron transfers from the occupied d-orbital of $\mathrm{Mo}^{\mathrm{IV}}$ to the substrate $\mathrm{X}-\mathrm{O} \sigma^{*}$ orbital. The energy gap between the two FMOs in the reactants (the Mo d HOMO and the $\mathrm{O}=\mathrm{S} \sigma^{*}$ substrate LUMO) is $\sim 6 \mathrm{eV}$ (Figure 8 top). The substrate $\mathrm{S}=\mathrm{O}$ bond must greatly elongate to bring down the energy of the substrate $\sigma^{*}$ orbital to interact with the Mo d HOMO, and polarize the $\mathrm{S}=\mathrm{O}$ bond to allow this electron transfer at a closer energy gap and with better overlap of the FMOs (Figure 8 top). Thus, the TS is late in $\mathrm{S}-\mathrm{O}$ bond elongation, and for the DMSO
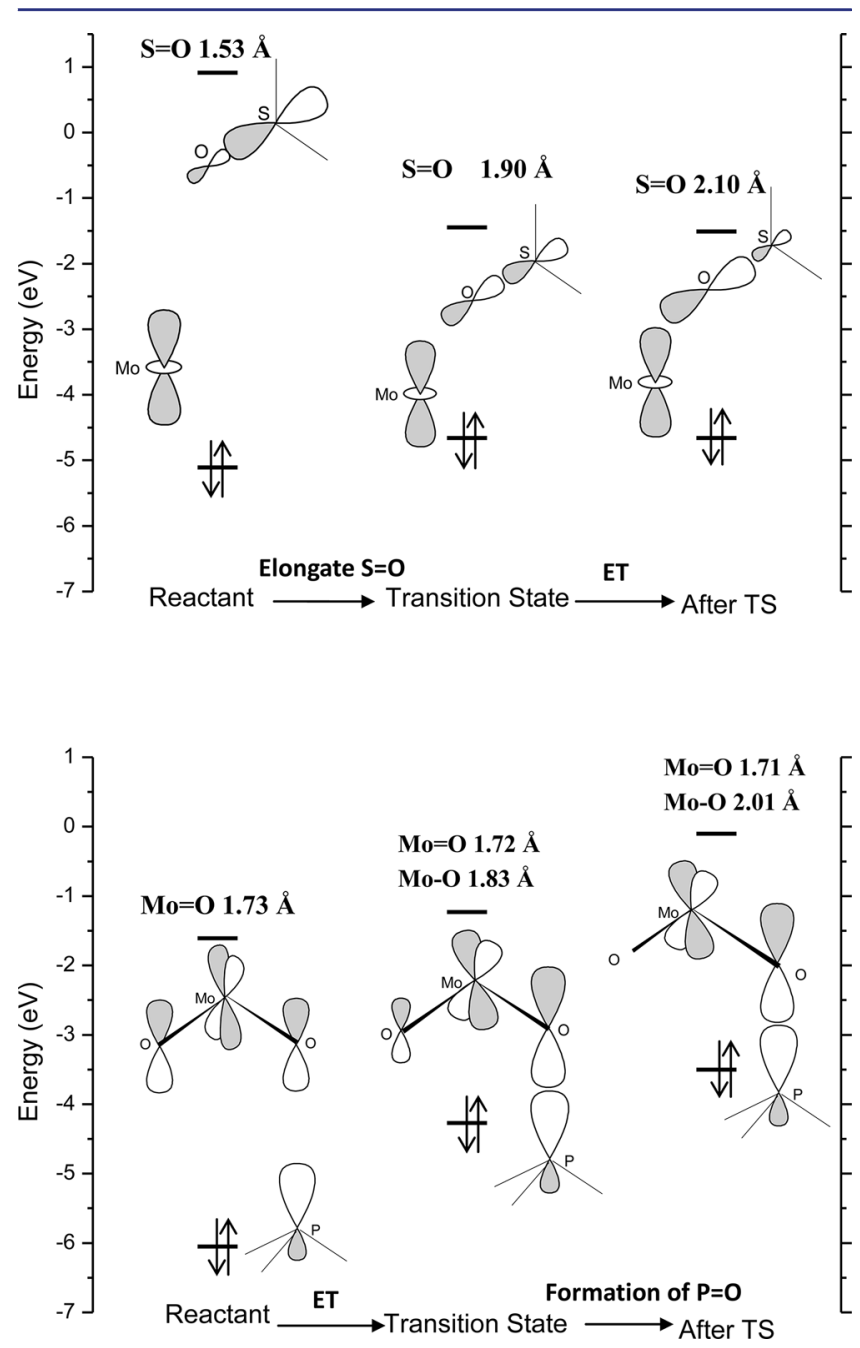

Figure 8. FMOs for DMSO oxo transfer to desoxo $\mathrm{Mo}^{\mathrm{IV}}$ (top), and bisoxo $\mathrm{Mo}^{\mathrm{VI}}$ oxo transfer to phosphine (bottom). reductase reaction, it is oxo atom transfer from the substrate that initiates the electron transfer from the Mo center.

For the reaction coordinate involving oxo transfer from bisoxo $\mathrm{Mo}^{\mathrm{VI}}$ to a phosphite substrate, in analogy to the sulfate oxidase enzyme reaction, electrons are transferred from the phosphorus lone pair into the low energy unoccupied Mo dorbital. This LUMO is a $\mathrm{d} \pi$ orbital with oxo $\mathrm{p} \pi$ character, with a calculated energy gap between the FMOs in the reactants of $\sim 4 \mathrm{eV}$ (Figure 8 bottom). This low energy splitting allows orbital mixing and thus electron transfer, from the substrate HOMO into the LUMO of the oxo Mo complex. Also, the oxo $\mathrm{p} \pi$ character of the Mo d-acceptor is large enough to overlap with the phosphorus lone pair with little additional polarization. Thus, the TS is early in Mo-O coordinate, and in this case, it is the transfer of an electron pair from the phosphite ester that induces cleavage of the Mo-O bond.

In general, when an oxo atom is transferred from a metal center to a substrate, an unoccupied d-orbital is involved which is close in energy to the substrate lone pair, allowing electron transfer. Relatively, when an organic oxo atom is transferred, the electron transfer is to the substrate-oxo $\sigma^{*}$ orbital. The $\sigma^{*}$ orbital is in general high in energy and has little oxo character due to the high electronegativity of $\mathrm{O}$ atom. Thus, the substrate oxo bond needs significant elongation to lower its energy and polarize to initiate the electron transfer.

4.3. Directionality. From thermodynamic considerations, the direction of these reactions is in part determined by the difference in oxo bond strengths (Table 2). Here, we use mdt (mdt $=1,2$-dimethylethene-1,2-dithiolate(2-)) ligation to be consistent with our previously published results for DMSO reductase reactions. It is shown in Table S2 that Mo mdt complexes have geometric and electronic structures similar to those of the Mo bdt complexes. For the phosphite oxidation reaction, the $\mathrm{P}=\mathrm{O}$ bond strength is $\sim 150 \mathrm{kcal} / \mathrm{mol}$, while the Mo-oxo bond in the $\mathrm{Mo}^{\mathrm{VI}}$ bisoxo complex is $106 \mathrm{kcal} / \mathrm{mol}$ (Table 2). This large difference in oxo bond strength drives the oxo transfer to the phosphite. In the DMSO reductase reaction, the $\mathrm{S}=\mathrm{O}$ bond is $91 \mathrm{kcal} / \mathrm{mol}$, while formation of mono $\mathrm{Mo}^{\mathrm{VI}}$-oxo bond gives $116 \mathrm{kcal} / \mathrm{mol}$; thus, it is energetically favorable to transfer the oxo from DMSO to the Mo center.

However, there are also kinetic considerations in the directionality of oxo transfer. In comparing the bisoxo $\mathrm{Mo}^{\mathrm{VI}}$ and the monooxo $\mathrm{Mo}^{\mathrm{VI}}$ complexes in the reaction involving oxo transfer to phosphite, the difference in the reaction enthalpy is $9 \mathrm{kcal} / \mathrm{mol}$, which reflects the bond strength difference (section 3.2). Their difference in the activation enthalpy is $3 \mathrm{kcal} / \mathrm{mol}$ (Figure S4), which gives an intrinsic barrier difference of only 1 $\mathrm{kcal} / \mathrm{mol}$. Both reactions are initiated by the phosphorus lone pair attacking the well-exposed oxo atom in the six-coordinate $\mathrm{Mo}^{\mathrm{VI}}$ complexes, and the structures of their TS's are very similar. The distortion of the Mo complexes into fivecoordinate products occurs after the TS. Electronically, both complexes use similar $\mathrm{d} \pi^{*}$ FMOs with similar energy gaps $(\sim 4$ $\mathrm{eV}$ in the reactant) and have similar phosphorus lone pair mixing into the Mo d LUMO $(\sim 30 \%)$ at the TS. Thus, oxo transfers from both bisoxo and monooxo $\mathrm{Mo}^{\mathrm{VI}}$ to phosphite have very similar reaction coordinates with a rate difference reflecting their difference in reaction energy.

Alternatively, it is also thermodynamically favorable to transfer an oxo atom from DMSO to both the des- and monooxo $\mathrm{Mo}^{\mathrm{IV}}$ complexes to form monooxo and bisoxo $\mathrm{Mo}^{\mathrm{VI}}$ complexes, respectively, with the same $9 \mathrm{kcal} / \mathrm{mol}$ difference. However, the difference in enthalpic barrier height, $\Delta H^{\ddagger}$, is 14 
$\mathrm{kcal} / \mathrm{mol}$ (Figure 9A, black vs green). This gives an intrinsic barrier for the monooxo to bisoxo reaction that is $9 \mathrm{kcal} / \mathrm{mol}$ higher than that for the des-to-mono oxo reaction.
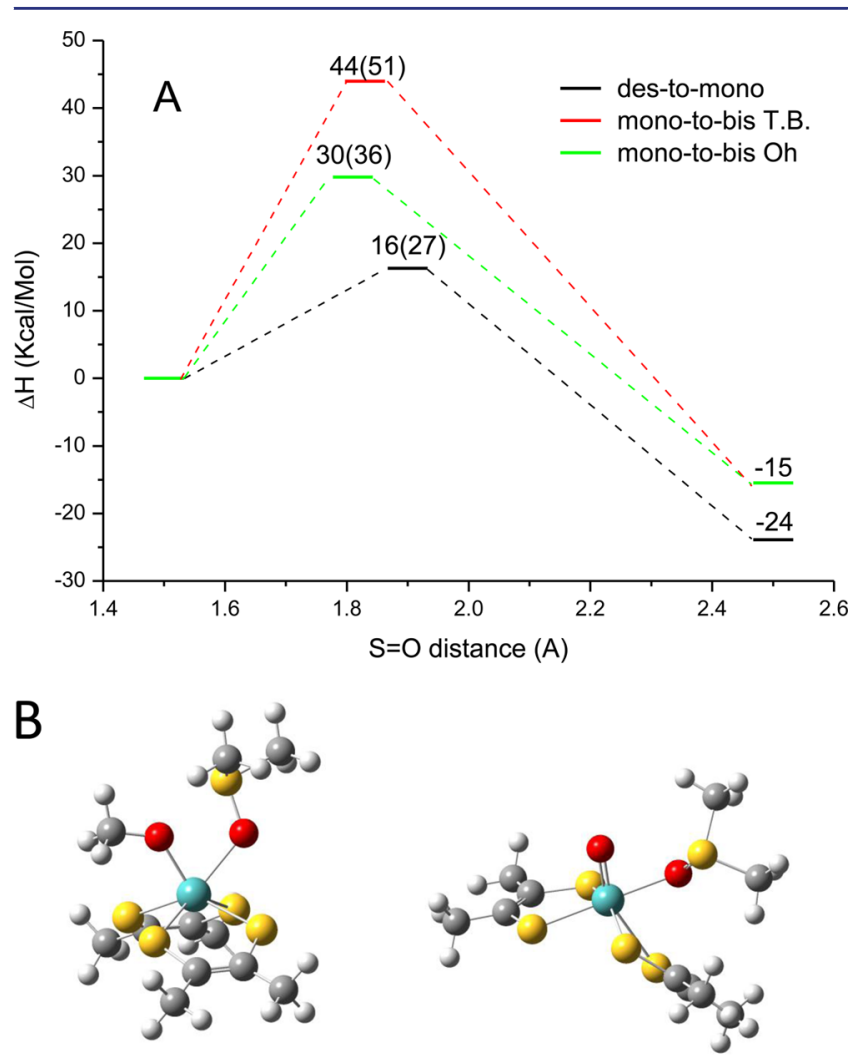

Figure 9. (A) Reaction coordinate for oxo transfer from DMSO to $\mathrm{Mo}^{\mathrm{IV}}$ complexes. Enthalpic barriers and intrinsic barriers (in parentheses) are indicated. T.B. stands for trigonal bipyramidal. The TS in red has a similar geometry to the TS in black. The starting point is where the Mo complex and the DMSO are $\sim 4 \AA$ away from each other. (B) Geometry of the DMSO bound intermediate structure for the des-to-mono oxo (left) and mono-to-bis oxo (right) coordinate. $\mathrm{Mo}-\mathrm{O}$ (DMSO) distance is constrained at $2.24 \AA$.

In the des-to-mono reaction, the reactant is a $5 \mathrm{C} \mathrm{Mo}^{\mathrm{IV}}$ complex. The methoxyl group distorts to open a site for DMSO to bind to form a 6C intermediate state (Figure 9B left). In this intermediate, DMSO-bound complex, the DMSO distortion energy is $3 \mathrm{kcal} / \mathrm{mol}$, and the distortion energy of the $\mathrm{Mo}^{\mathrm{IV}}$ desoxo complex is $18 \mathrm{kcal} / \mathrm{mol}$. There is $12 \mathrm{kcal} / \mathrm{mol}$ interaction energy between the two fragments, due to $14 \%$ donor and $2 \%$ backbonding interaction. Thus, the total energy of this DMSO bound state is $9 \mathrm{kcal} / \mathrm{mol}$ higher than that of the reactant, and there is an additional $7 \mathrm{kcal} / \mathrm{mol}$ required to reach the TS. In the mono-to-bis reaction, the five-coordinate $\mathrm{Mo}^{\mathrm{IV}}$ complex does not distort as described above, because of the higher energy required to distort the strong oxo bond (see trigonal bipyramidal (TB) TS in Figure 9A red). Instead, the dithiolene planes rotate to leave an open position for DMSO binding (Figure 9B right). The DMSO distortion energy is similar $(2 \mathrm{kcal} / \mathrm{mol})$, but the bis-dithiolene- $\mathrm{Mo}^{\mathrm{IV}}$-oxo distortion energy is larger than that for DMSO binding to the desoxo $\mathrm{Mo}^{\mathrm{IV}}(23 \mathrm{kcal} / \mathrm{mol})$. There is also a decreased interaction energy $(7 \mathrm{kcal} / \mathrm{mol}$ ) reflecting decreased donor bonding of the DMSO to $\mathrm{Mo}^{\mathrm{IV}}(8 \%)$ due to the strong oxo- $\mathrm{Mo}^{\mathrm{IV}}$ bond. This leads to a higher total energy $(18 \mathrm{kcal} / \mathrm{mol})$ to bind DMSO to the $\mathrm{Mo}^{\mathrm{IV}}=\mathrm{O}$ complex, and another $12 \mathrm{kcal} / \mathrm{mol}$ is required to reach the transition state.

In summary, for oxo transfer from six-coordinate $\mathrm{Mo}^{\mathrm{VI}}$ complexes to phosphite, electron transfer leads to oxo transfer. The electron density in the phosphorus lone pair orbital readily interacts with the oxo p-character in the low energy unoccupied metal d-orbital; thus, both the bis-to-mono or mono-to-des reactions are accessible. Alternately, for oxo transfer from DMSO to the five-coordinate $\mathrm{Mo}^{\mathrm{IV}}$ complexes, it is the oxo transfer that leads to electron transfer. This requires DMSO binding to the $\mathrm{Mo}^{\text {IV }}$ complex, which is more difficult in the presence of a strong oxo donor ligand.

4.4. Correlations to the Enzymes. With the results of the model studies, calculations can be used to consider the oxo transfer mechanism for native sulfite oxidase. Note that the substrate for the native enzyme is the fully deprotonated sulfite, ${ }^{54}$ while the model complex in section 3.3.2 was not stable at the $\mathrm{pH} \sim 8$ where $\mathrm{SO}_{3}{ }^{2-}$ dominates. By systematically varying the substrate and the ligation of the Mo site, the results from the $\left[\mathrm{Mo}^{\mathrm{VI}} \mathrm{O}_{2}(\mathrm{mnt})_{2}\right]^{2-}$ complex can be extended to the enzyme active site (reaction numbers below correspond to those in Table 3).

Comparison of reactions (1) and (4) shows that for the same six-coordinate $\left[\mathrm{Mo}^{\mathrm{VI}} \mathrm{O}_{2}(\mathrm{mnt})_{2}\right]^{2-}$ complex, oxo transfer to $\mathrm{SO}_{3}{ }^{2-}$ has a much lower barrier than to phosphite. The dianionic $\mathrm{SO}_{3}{ }^{2-}$ has more charge density, thus its lone pair donor HOMO is closer in energy to the LUMO of the Mo bisoxo complex. Thus, even less distortion is required for the overlap of the FMOs for the electron transfer to induce oxo transfer to sulfite and there is an even earlier transition state (Table 3, shorter Mo-O distance and higher Mo-O bond order).

Table 3. Computational Comparison of Oxo Transfer from $\mathrm{Mo}^{\mathrm{VI}} \mathrm{O}$ Dithiolene Complex to Two Different Substrates

\begin{tabular}{|c|c|c|c|c|c|c|c|c|}
\hline rxn no. & $\mathrm{Mo}^{\mathrm{VI}}$ site & substrate & $\begin{array}{c}\Delta H^{\mathrm{rxn}} \\
(\mathrm{kcal} / \mathrm{mol})\end{array}$ & $\begin{array}{c}\Delta H^{\ddagger} \\
(\mathrm{kcal} / \mathrm{mol})^{a}\end{array}$ & $\underset{(\AA)}{\text { Mo-O distance at TS }}$ & $\begin{array}{c}\mathrm{Mo}-\mathrm{O} \text { MBO at } \\
\text { TS }\end{array}$ & $\begin{array}{c}\text { energy gap } \\
(\mathrm{eV})^{B}\end{array}$ & $\mathrm{mix}^{c}$ \\
\hline (1) & {$\left[\mathrm{MoO}_{2}(\mathrm{mnt})_{2}\right]^{2-}$} & $\mathrm{P}(\mathrm{OMe})_{3}$ & -48 & $11(30)$ & 1.83 & 1.17 & 4.2 & $21 \%$ \\
\hline (4) & {$\left[\mathrm{MoO}_{2}(\mathrm{mnt})_{2}\right]^{2-}$} & $\mathrm{SO}_{3}^{2-}$ & -39 & $1(13)$ & 1.78 & 1.54 & 1.2 & $35 \%$ \\
\hline (5) & {$\left[\mathrm{MoO}_{2}(\mathrm{mnt})\left(\mathrm{SCH}_{3}\right)\right]^{-}$} & $\mathrm{P}(\mathrm{OMe})_{3}$ & -25 & $14(25)$ & 1.83 & 1.17 & 4.0 & $23 \%$ \\
\hline (6) & {$\left[\mathrm{MoO}_{2}(\mathrm{bdt})\left(\mathrm{SCH}_{3}\right)\right]^{-}$} & $\mathrm{P}(\mathrm{OMe})_{3}$ & -20 & $16(25)$ & 1.85 & 1.13 & 4.0 & $22 \%$ \\
\hline$(7)^{d}$ & {$\left[\mathrm{MoO}_{2}(\mathrm{bdt})\left(\mathrm{SCH}_{3}\right)\right]^{-}$} & $\mathrm{SO}_{3}{ }^{2-}$ & -23 & $3(12)$ & 1.82 & 1.41 & 1.4 & $41 \%$ \\
\hline$(8)^{e}$ & {$\left[\mathrm{MoO}_{2}(\mathrm{bdt})\left(\mathrm{SCH}_{3}\right)\right]^{-}$} & $\mathrm{SO}_{3}^{2-}$ & -12 & $32(38)$ & 1.82 & 1.39 & 1.1 & $39 \%$ \\
\hline
\end{tabular}

${ }^{a}$ Intrinsic barriers show in parentheses. ${ }^{b}$ Energy gap between the substrate lone pair and the LUMO of the Mo site in reactant. ${ }^{c}$ Amount of substrate lone pair mixed into the unoccupied orbitals at the transition state. ${ }^{d}$ In this reaction, the product sulfate stayed bound to the Mo site, which remains a five-coordinate site. ${ }^{e}$ The reaction was carried out with a dielectric constant of 4 . There is no stable ES or EP complex, and the resultant fourcoordinate $\mathrm{Mo}^{\mathrm{IV}}$ site rearranged to a trigonal pyramidal geometry. 
In reaction (1), the Mo site goes from six-coordinate to fivecoordinate, while in reaction (5) one of the dithiolenes is replaced with one thiolate, and the oxo transfer to phosphite corresponds to a five-coordinate to four-coordinate conversion. Reaction (5) has less driving force than (1) due to the difference in Mo-oxo bond strengths $(102 \mathrm{kcal} / \mathrm{mol}$ for the six-coordinate and $126 \mathrm{kcal} / \mathrm{mol}$ for the five-coordinate $\mathrm{Mo}^{\mathrm{VI}}$ bisoxo complex); however, the intrinsic barrier for reaction (5) is lower (Table 3). For the six-coordinate $\left[\mathrm{Mo}^{\mathrm{VI}} \mathrm{O}_{2}(\mathrm{mnt})_{2}\right]^{2-}$, the two oxo atoms are equivalent ( $9 \%$ of each in the LUMO, Figure 10A), and need to polarize toward the oxo that is
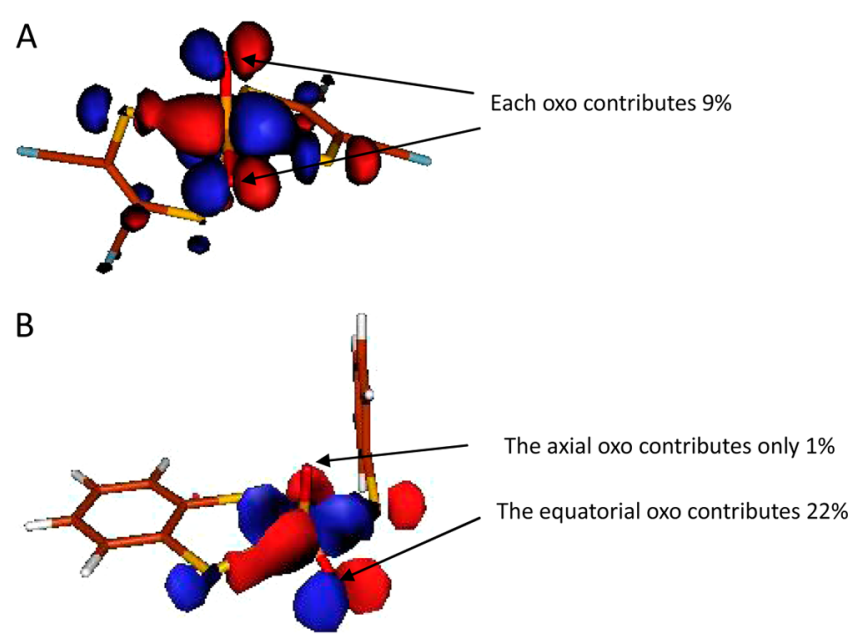

Figure 10. (A) LUMO of six-coordinate $\mathrm{Mo}^{\mathrm{VI}} \mathrm{O}_{2}$ site. The two oxo atoms are identical in the reactant. (B) LUMO of the five-coordinate $\mathrm{Mo}^{\mathrm{VI}}$ site. The equatorial oxo atom has a much larger contribution than the axial oxo atom.

transferred (Figure $8 \mathrm{~B}$ ). In the five-coordinate $\left[\mathrm{Mo}^{\mathrm{VI}} \mathrm{O}_{2}(\mathrm{mnt})\right.$ $\left.\left(\mathrm{SCH}_{3}\right)\right]^{-}$complex, the two oxo atoms are nonequivalent with the equatorial oxo contributing $22 \%$ to the LUMO ( $1 \%$ for the axial oxo, Figure 10B). This activates the equatorial oxo for transfer, consistent with the selectivity of the enzyme.

Another advantage of the five-coordinate $\mathrm{Mo}^{\mathrm{VI}}$ bisoxo complex is that for a six-coordinate dithiolene complex, the two dithiolene planes have to rotate by about $90^{\circ}$ for each reaction cycle. From section 3.3.1, this rotation costs $\sim 25 \mathrm{kcal} /$ mol. The energy would be even higher in the enzyme where the pyranopterin extends into the protein. Less dithiolene rearrangement is required in the five-coordinate $\mathrm{Mo}^{\mathrm{VI}}$ bisoxo site as the major change is simply equatorial oxo transfer.

In going from reaction (5) to (6), the mnt is changed into the bdt, without a change in the intrinsic barrier, and reaction (7) simulates the active site of the native enzyme with the native substrate. Relative to reaction (6) with phosphite, sulfite lowers the reaction barrier and leads to an earlier transition state, as discussed above. The product $\mathrm{SO}_{4}{ }^{2-}$ remains bound to the $\mathrm{Mo}^{\mathrm{IV}}$ monooxo product complex. The calculated $\Delta G^{\ddagger}$ is 4 $\mathrm{kcal} / \mathrm{mol}$, while based on the rate constant $\left(7.0 \times 10^{6} \mathrm{M}^{-1} \mathrm{~s}^{-1}\right.$ at $298 \mathrm{~K}){ }^{54}$ the experimental $\Delta G^{\ddagger}$ for chicken liver sulfite oxidase is $\sim 7 \mathrm{kcal} / \mathrm{mol}$. All the calculations above were done in acetonitrile, which has a dielectric constant of 36 . However, in proteins, the dielectric constant is decreased. ${ }^{55}$ Reaction (8) repeated reaction (7) with a dielectric constant of 4. This resulted in a large increase in reaction barrier with no stable ES complex, due to the increase in Coulomb repulsion. The Mo site has a total charge of -1 , while the sulfite has a charge of
-2. This suggests that in SO, the protein environment contributes to the substrate binding (a positively charged pocket with conserved tyrosine, histidine, and arginine residues) to form the ES complex to lower the barrier for oxo transfer, ${ }^{56,57}$ while the pyranopterin cofactor functions as a pathway to reoxidize the Mo site subsequent to the oxo transfer. $^{22,58}$ [Note that the $\mathrm{O}_{\mathrm{ax}}-\mathrm{Mo}-\mathrm{S}_{\text {thiolate }}-\mathrm{C}$ dihedral angle in the optimized structure is different from that in the crystal structure $\left(148^{\circ}\right.$ vs $\left.78^{\circ}\right)$. However, this dihedral angle distortion only costs a few $\mathrm{kcal} / \mathrm{mol}$ of energy, consistent with ref 55.]

In contrast, the experimental $\Delta G^{\neq}$for Escherichia coli DMSO reductase is $\sim 9 \mathrm{kcal} / \mathrm{mol}$ (based on the rate constant $4.3 \times 10^{5}$ $\mathrm{M}^{-1} \mathrm{~s}^{-1}$ at $\left.298 \mathrm{~K}\right),{ }^{59}$ much lower than the value calculated for the model complex $(30 \mathrm{kcal} / \mathrm{mol}){ }^{10}$ This indicates that the geometry of the enzyme active site is distorted toward the transition state by the protein environment to assist the oxo transfer reaction in DMSOr as suggested by Hall and coworkers ${ }^{15}$ and Kirk and co-workers. ${ }^{13}$ Also, in this class of oxo transfer enzymes, the two pyranopterins are found to be structurally different with the protein tuning one to be an electron conduit, to effectively reduce the oxidized state. ${ }^{58}$

\section{CONCLUSIONS}

This study provides insight into the oxo transfer reaction in sulfite oxidase, based on experimental and computational results on its model complexes, and its relation to our previous studies on related DMSO reductase models. In DMSOr, it is the oxo transfer that leads to electron transfer, while in SO, oxo transfer is initiated by the electron transfer. This difference reflects the large energy gap between the LUMO of DMSO and $\mathrm{d} \pi$ HOMO in the $\mathrm{Mo}^{\text {IV }}$ desoxo complex relative to the small energy gap between the sulfite lone pair HOMO and the $\mathrm{d} \pi$ orbital-based LUMO of the $\mathrm{Mo}^{\mathrm{VI}}$ bisoxo complex. The fivecoordinate $\mathrm{Mo}^{\mathrm{VI}}$ bisoxo active site of $\mathrm{SO}$ activates the equatorial oxo, and minimizes the reorganization energy over the reaction cycle.

\section{ASSOCIATED CONTENT}

\section{S Supporting Information}

Fits to the second derivative of the $\mathrm{S}$ K-edge XAS data; electronic structures of $\left[\mathrm{Mo}^{\mathrm{IV}}(\mathrm{OSi})(\mathrm{bdt})_{2}\right]^{-}$and $\left[\mathrm{Mo}^{\mathrm{VI}} \mathrm{O}-\right.$ $\left.(\mathrm{OSi})(\mathrm{bdt})_{2}\right]^{-}$complexes from our previous study; reaction coordinate of reaction (2) without proton shift; reaction coordinate and TS structure compare for oxo transfer from $\mathrm{Mo}^{\mathrm{VI}}$ complexes to phosphine; fragment energy contribution and TS structure compare for oxo transfer from DMSO to $\mathrm{Mo}^{\mathrm{IV}}$ complexes; computational results with BP86 functional; computational results comparison of Mo complexes with bdt, mnt, and mdt ligands. Cartesian coordinates for all optimized structures in zipped xyz files. This material is available free of charge via the Internet at http://pubs.acs.org.

\section{AUTHOR INFORMATION}

\section{Corresponding Authors}

holm@chemistry.harvard.edu

hodgson@ssrl.slac.stanford.edu

hedman@ssrl.slac.stanford.edu

solomone@stanford.edu

\section{Present Address}

${ }^{\perp}$ Target Discovery, Inc., Palo Alto, CA 94303

Notes

The authors declare no competing financial interest. 


\section{ACKNOWLEDGMENTS}

This study was supported by NSF grant (CHE 0948211, E.I.S. at Stanford University and CHE 0846397, R.H.H. at Harvard University) and NIH Grant (P41GM103393, K.O.H.). Use of the Stanford Synchrotron Radiation Lightsource, SLAC National Accelerator Laboratory, is supported by the U.S. Department of Energy, Office of Science, Office of Basic Energy Sciences under Contract No. DE-AC02-76SF00515. The SSRL Structural Molecular Biology Program is supported by the DOE Office of Biological and Environmental Research, and by the National Institutes of Health, National Institute of General Medical Sciences (including P41GM103393).

\section{REFERENCES}

(1) Hille, R. Trends Biochem. Sci. 2002, 27, 360.

(2) Burgess, B. K.; Lowe, D. J. Chem. Rev. 1996, 96, 2983.

(3) Howard, J. B.; Rees, D. C. Chem. Rev. 1996, 96, 2965.

(4) Holm, R. H.; Kennepohl, P.; Solomon, E. I. Chem. Rev. 1996, 96, 2239 .

(5) Kisker, C.; Schindelin, H.; Rees, D. C. Annu. Rev. Biochem. 1997, 66, 233.

(6) Hille, R. Chem. Rev. 1996, 96, 2757.

(7) Schwarz, G.; Mendel, R. R.; Ribbe, M. W. Nature 2009, 460, 839.

(8) Tenderholt, A. L.; Szilagyi, R. K.; Holm, R. H.; Hodgson, K. O.; Hedman, B.; Solomon, E. I. J. Inorg. Biochem. 2007, 101, 1594.

(9) Enemark, J. H.; Cooney, J. J. A.; Wang, J.-J.; Holm, R. H. Chem. Rev. 2004, 104, 1175.

(10) Tenderholt, A. L.; Wang, J.-J.; Szilagyi, R. K.; Holm, R. H.; Hodgson, K. O.; Hedman, B.; Solomon, E. I. J. Am. Chem. Soc. 2010, $132,8359$.

(11) George, G. N.; Nelson, K. J.; Harris, H. H.; Doonan, C. J.; Rajagopalan, K. V. Inorg. Chem. 2007, 46, 3097.

(12) Pushie, M. J.; Cotelesage, J. J. H.; Lyashenko, G.; Hille, R.; George, G. N. Inorg. Chem. 2013, 52, 2830.

(13) McNaughton, R. L.; Lim, B. S.; Knottenbel, S. Z.; Holm, R. H.; Kirk, M. L. J. Am. Chem. Soc. 2008, 130, 4628.

(14) Hofmann, M. Inorg. Chem. 2008, 47, 5546.

(15) Webster, C. E.; Hall, M. B. J. Am. Chem. Soc. 2001, 123, 5820.

(16) Lim, B. S.; Willer, M. W.; Miao, M.; Holm, R. H. J. Am. Chem. Soc. 2001, 123, 8343.

(17) Das, S. K.; Chaudhury, P. K.; Biswas, D.; Sarkar, S. J. Am. Chem. Soc. 1994, 116, 9061.

(18) Thomson, L. M.; Hall, M. B. J. Am. Chem. Soc. 2001, 123, 3995.

(19) Schultz, B. E.; Gheller, S. F.; Muetterties, M. C.; Scott, M. J.; Holm, R. H. J. Am. Chem. Soc. 1993, 115, 2714.

(20) Kail, B. W.; Pérez, L. M.; Zarić, S. D.; Millar, A. J.; Young, C. G.; Hall, M. B.; Basu, P. Chem-Eur. J. 2006, 12, 7501.

(21) Mitra, J.; Sarkar, S. Inorg. Chem. 2013, 52, 3032.

(22) Peariso, K.; Helton, M. E.; Duesler, E. N.; Shadle, S. E.; Kirk, M. L. Inorg. Chem. 2007, 46, 1259.

(23) Tucci, G. C.; Donahue, J. P.; Holm, R. H. J. Am. Chem. Soc. 1998, 37, 1602.

(24) Solomon, E. I.; Hedman, B.; Hodgson, K. O.; Dey, A.; Szilagyi, R. K. Coord. Chem. Rev. 2005, $249,97$.

(25) Sarangi, R.; George, S. D.; Rudd, D. J.; Szilagyi, R. K.; Ribas, X.; Rovira, C.; Almeida, M.; Hodgson, K. O.; Hedman, B.; Solomon, E. I. J. Am. Chem. Soc. 2007, 129, 2316.

(26) Dey, A.; F. E, J., Jr.; Adams, M. W. W.; Babini, E.; Takahashi, Y.; Fukuyama, K.; Hodgson, K. O.; Hedman, B.; Solomon, E. I. Science 2007, 318, 1464.

(27) Donahue, J. P.; Goldsmith, C. R.; Nadiminti, U.; Holm, R. H. J. Am. Chem. Soc. 1998, 120, 12869.

(28) George, G. N.; EXAFSPAK; Stanford Synchrotron Radiaton Laboratory: Menlo Park, CA, 1990.

(29) Tenderholt, A. L.; Hedman, B.; Hodgson, K. O. AIP Conf. Proc. 2006, 882, 105 .
(30) Frisch, M. J.; Trucks, G. W.; Schlegel, H. B.; Scuseria, G. E.; Robb, M. A.; Cheeseman, J. R.; Scalmani, G.; Barone, V.; Mennucci, B.; Petersson, G. A.; Nakatsuji, H.; Caricato, M.; Li, X.; Hratchian, H. P.; Izmaylov, A. F.; Bloino, J.; Zheng, G.; Sonnenberg, J. L.; Hada, M.; Ehara, M.; Toyota, K.; Fukuda, R.; Hasegawa, J.; Ishida, M.; Nakajima, T.; Honda, Y.; Kitao, O.; Nakai, H.; Vreven, T.; Montgomery, J. A.; Peralta, J. E.; Ogliaro, F.; Bearpark, M.; Heyd, J. J.; Brothers, E.; Kudin, K. N.; Staroverov, V. N.; Kobayashi, R.; Normand, J.; Raghavachari, K.; Rendell, A.; Burant, J. C.; Iyengar, S. S.; Tomasi, J.; Cossi, M.; Rega, N.; Millam, J. M.; Klene, M.; Knox, J. E.; Cross, J. B.; Bakken, V.; Adamo, C.; Jaramillo, J.; Gomperts, R.; Stratmann, R. E.; Yazyev, O.; Austin, A. J.; Cammi, R.; Pomelli, C.; Ochterski, J. W.; Martin, R. L.; Morokuma, K.; Zakrzewski, V. G.; Voth, G. A.; Salvador, P.; Dannenberg, J. J.; Dapprich, S.; Daniels, A. D.; Farkas; Foresman, J. B.; Ortiz, J. V.; Cioslowski, J.; Fox, D. J. Gaussian 09; Gaussian, Inc.: Wallingford, CT, 2009.

(31) Becke, A. D. J. Chem. Phys. 1993, 98, 5648.

(32) Perdew, J. P. Phys. Rev. B 1986, 33, 8822.

(33) Lee, C.; Yang, W.; Parr, R. G. Phys. Rev. B 1988, 37, 785.

(34) Andrae, D.; Häußermann, U.; Dolg, M.; Stoll, H.; Preuß, H. Theor. Chim. Acta 1990, 77, 123.

(35) Hratchian, H. P.; Schlegel, H. B. In Theory and Application of Computational Chemistry: The First Forty Years; Dykstra, C. E., Frenking, G., Kim, K. S., Scuseria, G. E., Eds.; Elsevier B. V.: 2005; p 195.

(36) Tomasi, J.; Mennucci, B.; Cammi, R. Chem. Rev. 2005, 105, 2999.

(37) Tenderholt, A. L. In QMForge, V2.1; Stanford University: Stanford, CA, 2007.

(38) O’boyle, N. M.; Tenderholt, A. L.; Langner, K. M. J. Comput. Chem. 2008, 29, 839.

(39) Musgrave, K. B.; Donahue, J. P.; Lorber, C.; Holm, R. H.; Hedman, B.; Hodgson, K. O. J. Am. Chem. Soc. 1999, 121, 10297.

(40) Tenderholt, A. L.; Szilagyi, R. K.; Holm, R. H.; Hodgson, K. O.; Hedman, B.; Solomon, E. I. Inorg. Chem. 2008, 47, 6382.

(41) Szilagyi, R. K.; Lim, B. S.; Glaser, T.; Holm, R. H.; Hedman, B.; Hodgson, K. O.; Solomon, E. I. J. Am. Chem. Soc. 2003, 125, 9158.

(42) Lee, S. C.; Holm, R. H. Inorg. Chim. Acta 2008, 361, 1166.

(43) Watt, G. D.; McDonald, J. W.; Newton, W. E. J. Less-Common Met. 1977, 54, 415.

(44) Holm, R. H.; Donahue, J. P. Pohyhedron 1993, 12, 571.

(45) Harlan, E. W.; Berg, J. M.; Holm, R. H. J. Am. Chem. Soc. 1986, $108,6992$.

(46) Rappe, A. K.; Goddard, W. A. J. Am. Chem. Soc. 1982, 104, 3287.

(47) Mayer, I. Chem. Phys. Lett. 1983, 97, 270.

(48) Thapper, A.; Deeth, R. J.; Nordlander, E. Inorg. Chem. 2002, 41, 6695.

(49) Pauling, L. J. Am. Chem. Soc. 1947, 69, 542.

(50) Pal, K.; Chaudhury, P. K.; Sarkar, S. Chem.-Asian J. 2007, 2, 956.

(51) Marcus, R. A. J. Phys. Chem. 1968, 72, 891.

(52) Chow, M. S.; Liu, Lei V.; Solomon, E. I. Proc. Natl. Acad. Sci. U.S.A. 2008, 105, 13241

(53) Tenderholt, A. L.; Hodgson, K. O.; Hedman, B.; Holm, R. H.; Solomon, E. I. Inorg. Chem. 2012, 51, 3436.

(54) Brody, M. S.; Hille, R. Biochemistry 1999, 38, 6668.

(55) Li, L.; Li, C.; Zhang, Z.; Alexov, E. J. Chem. Theory Comput. 2013, 9, 2126.

(56) Rajapakshe, A.; Johnson-Winters, K.; Nordstrom, A. R.; Meyers, K. T.; Emesh, S.; Astashkin, A. V.; Enemark, J. H. Biochem. 2010, 49, 5154.

(57) Bailey, S.; Rapson, T.; Johnson-Winters, K.; Astashkin, A. V.; Enemark, J. H.; Kappler, U. J. Biol. Chem. 2009, 284, 2053.

(58) Rothery, R. A.; Stein, B.; Solomonson, M.; Kirk, M. L.; Weiner, J. H. Proc. Natl. Acad. Sci. U.S.A. 2012, 109, 14773.

(59) Cobb, N.; Hemann, C.; Polsinelli, G. A.; Ridge, J. P.; McEwan, A. G.; Hille, R. J. Biol. Chem. 2007, 282, 35519. 